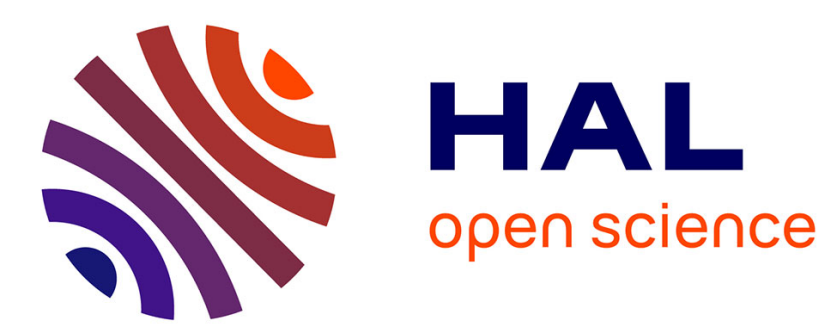

\title{
A longitudinal examination of nurses' need satisfaction profiles: A latent transition analysis
}

Tiphaine Huyghebaert-Zouaghi, Alexandre J.S. Morin, Jacques Forest, Evelyne Fouquereau, Nicolas Gillet

\section{- To cite this version:}

Tiphaine Huyghebaert-Zouaghi, Alexandre J.S. Morin, Jacques Forest, Evelyne Fouquereau, Nicolas Gillet. A longitudinal examination of nurses' need satisfaction profiles: A latent transition analysis. Current Psychology, 2020, 10.1007/s12144-020-00972-1 . hal-02913715

\section{HAL Id: hal-02913715 \\ https://hal.science/hal-02913715}

Submitted on 28 Jun 2021

HAL is a multi-disciplinary open access archive for the deposit and dissemination of scientific research documents, whether they are published or not. The documents may come from teaching and research institutions in France or abroad, or from public or private research centers.
L'archive ouverte pluridisciplinaire HAL, est destinée au dépôt et à la diffusion de documents scientifiques de niveau recherche, publiés ou non, émanant des établissements d'enseignement et de recherche français ou étrangers, des laboratoires publics ou privés. 
Running Head : Need Satisfaction Profiles

A Longitudinal Examination of Nurses' Need Satisfaction Profiles: A Latent Transition Analysis

Tiphaine Huyghebaert-Zouaghi ${ }^{\mathrm{a} *}$, Alexandre J.S. Morin ${ }^{\mathrm{b} *}$, Jacques Forest $^{\mathrm{c}}$, Evelyne Fouquereau ${ }^{\mathrm{d}}$, Nicolas Gillet ${ }^{\mathrm{d}}$

${ }^{a}$ Université de Reims Champagne Ardenne, France (E.A. 6291 Laboratoire C2S)

${ }^{\mathrm{b}}$ Concordia University, Canada (Substantive-Methodological Synergy Research Laboratory)

${ }^{\mathrm{c}}$ École des Sciences de la Gestion, Université du Québec à Montréal, Canada (Department of Organization and Human Resources)

${ }^{\mathrm{d}}$ Université de Tours, France (E.E. 1901 QualiPsy)

* The first two authors (T.H. \& A.J.S.M.) contributed equally to this article. Both should thus be considered first authors.

\title{
Corresponding author :
}

Tiphaine Huyghebaert-Zouaghi

Université de Reims

Laboratoire C2S (E.A. 6291)

UFR Lettres et Sciences Humaines, Département de Psychologie

57 rue Pierre Taittinger, 51100 Reims, France

tiphaine.huyghebaert@univ-reims.fr

This is the prepublication version of the following manuscript:

Huyghebaert-Zouaghi, Morin, A. J. S., Forest, J., Fouquereau, E., \& Gillet, N. (In Press). A

longitudinal examination of nurses' need satisfaction profiles: A latent transition analysis. Current

Psychology. Early view. doi : 10.1007/s12144-020-00972-1

(C) 2020. This paper is not the copy of record and may not exactly replicate the authoritative document published in Current Psychology.

\begin{abstract}
This study examined within-person and within-sample stability of need satisfaction profiles over a three-month period among a sample of 1319 nurses. This study also considered the implications of these profiles for employee functioning (vigor, need for recovery, and job satisfaction), as well as the role of perfectionism and job crafting in predicting profile membership. Results revealed four distinct need satisfaction profiles, which proved to have the same structure, and size, across measurement points. The dimensions of perfectionism and those of job crafting showed well-differentiated patterns of association with the profiles. Results also revealed that the key driver of the most adaptive functioning was the presence of balanced levels of global and specific need satisfaction of at least a moderate magnitude.
\end{abstract}

Keywords: Need satisfaction profiles; Self-determination theory; Job crafting; Nurses; Well-being 
As people spend more and more time at work (Hiemer \& Andresen, 2019) psychological health has become an important concern for organizations and society (Hassard, Theoh, Visockaite, Dewe, \& Cox, 2018). This concern has led researchers to identify a variety of psychosocial resources on which to act to promote employee functioning (Bakker \& Demerouti, 2017). When it comes to the psychological mechanisms that may explain the impact of the work environment on employee functioning, self-determination theory (SDT; Deci \& Ryan, 2000) has consistently shown that the ability of workplaces to satisfy employees' basic psychological needs for autonomy, competence, and relatedness plays a key role in promoting well-being (see Deci, Olafsen, \& Ryan, 2017). The need for autonomy refers to individuals' need to feel volitional and responsible for their actions. The need for competence underscores one's need to feel efficient when interacting with their social environment and to have opportunities to express their abilities. Finally, the need for relatedness refers to the need to feel secure in one's relationships and to be able to rely on others.

SDT showed that it is through the satisfaction of these needs that the social environment is able to influence workers' psychological adjustment. While studies supported the role of need satisfaction as a whole (e.g., Olafsen, Halvari, Forest, \& Deci, 2015), other research suggests differentiated relations between the satisfaction of each of these three needs and various outcomes (e.g., Trépanier, Fernet, \& Austin, 2016). Yet, these studies have generally failed to consider the combinatory effects of the general experience of global need satisfaction, together with the specific experience of satisfaction of each of the needs for autonomy, competence, and relatedness (Gillet, Morin, Huart, Colombat, \& Fouquereau, 2019; Sánchez-Oliva, Morin, Teixeira, et al., 2017). The present study addresses this gap by: (1) exploring the nature of employees' need satisfaction profiles by jointly considering their levels of global need satisfaction and the satisfaction of each specific psychological need; (2) examining the role of individual orientations (perfectionism and job crafting) in the prediction of profile membership; (3) appraising the impact of profile membership on employee functioning (vigor, need for recovery, and job satisfaction); and (4) using a longitudinal design allowing for a verification of within-person and within-sample profile stability (Kam, Morin, Meyer, \& Topolnytsky, 2016).

\section{Literature Review}

\section{The Combined Role of Global and Specific Levels of Need Satisfaction}

Need satisfaction has repeatedly been shown to be instrumental for employees' optimal functioning (Hetland, Hetland, Bakker et al., 2015; Trépanier, Fernet, \& Austin, 2015), whereas lack of need satisfaction was demonstrated to yield maladaptive outcomes (Huyghebaert, Gillet, Lahiani, DuboisFleury, \& Fouquereau, 2018). Some of these conclusions hold true irrespective of whether researchers rely on a total score of need satisfaction encompassing all three needs (Huyghebaert, Gillet, Lahiani et al., 2018; Trépanier, Fernet et al., 2015), or whether they rely on distinct measures of the needs for autonomy, competence, and relatedness (Trépanier et al., 2016). Indeed, a premise of SDT is that all three psychological needs must be fulfilled together for psychological well-being to occur (Deci \& Ryan, 2000). The unbalanced satisfaction of only one need has been proposed to lead to less optimal functioning (Ryan, 1995). SDT has also suggested that the benefits of need satisfaction should be greater when all three psychological needs are satisfied in a balanced manner (i.e., at a same level) rather than in a way that differs across all three needs (i.e., imbalance; Sheldon \& Niemiec, 2006). These perspectives all stress the need to investigate the combined effects of the satisfaction of each of the three needs through approaches going beyond the sole examination of their additive contributions.

Few studies have explored the combined effects of need satisfaction in different life domains (Chang, 2012; Dysvik, Kuvaas, \& Gagné, 2013; Sheldon \& Filak, 2008; Sheldon \& Niemiec, 2006; Vansteenkiste, Lens, Soenens, \& Luyckx, 2006). These studies have shown that all three needs have a beneficial effect for motivation and well-being (Sheldon \& Filak, 2008; Sheldon \& Niemiec, 2006; Vansteenkiste et al., 2006). However, studies have also shown that these basic needs have more than simple additive effects (Chang, 2012; Vansteenkiste et al., 2006). In the work setting, research has shown that competence need satisfaction was positively linked to intrinsic motivation when combined with high levels of autonomy need satisfaction or with low levels of relatedness need satisfaction, and that relatedness need satisfaction was positively related to intrinsic motivation when combined with high levels of autonomy need satisfaction (Dysvik et al., 2013).

Sheldon and Niemiec (2006) also showed that a balanced level of satisfaction of all three needs was associated with higher levels of intrinsic motivation among college students. Similar evidence was reported among working employees. Yet, need balance did not account for additional variance in 
intrinsic motivation once the effects of all three needs and their interactions were included (Dysvik et al., 2013). However, both of these studies relied on an indirect measurement of need balance, obtained via difference scores, known to be particularly sensitive to measurement errors (Edwards, 2002). Although interpreted as reflecting need balance, these difference scores come from a measure of need imbalance, reverse-coded for an analytical purpose. In addition, Dysvik et al. (2013) contrasted interaction and (im)balance effects by adding the need balance difference scores to a regression already incorporating interaction effects, and thus already providing an implicit representation of balance effects (Cheung, 2009; Edwards, 2009). This statistical redundancy could account for the limited added-value of need (im)balance in Dysvik et al.'s (2013) study. Recent research suggests that these shortcomings can be overcome by a more direct measure of need (im)balance.

Indeed, despite being conceptually distinct, the needs for autonomy, competence, and relatedness tend to be moderately to highly correlated (e.g., Jang, Reeve, Ryan, \& Kim, 2009; Vansteenkiste et al., 2006). This observation has led to a series of psychometric investigations into the multidimensional structure of these ratings. These studies have shown that need satisfaction was best represented as a function of two distinct components. The first of those components provides a direct estimate of participants' global levels of need satisfaction across all three needs, while the second provides an equally direct estimate of the specific levels of satisfaction of the needs for autonomy, competence, and relatedness left unaccounted for by this global level (i.e., a direct estimate of imbalance). This operationalization of need satisfaction has been supported in the work (Bidee, Vantilborgh, Pepermans, Griep, \& Hofmans, 2016; Gillet, Morin, Huart et al., 2019; Sánchez-Oliva et al., 2017), education (Garn, Morin, \& Lonsdale, 2018; Gillet, Morin, Huyghebaert et al., 2019), sport (Brunet, Gunnell, Teixeira, Sabiston, \& Bélanger, 2016), and global life (Tóth-Király, Morin, Bőthe, Orosz, \& Rigó, 2018) domains. These studies show that it is possible to obtain a direct estimate of global levels of need satisfaction across all three needs, accompanied by a complementary non-redundant estimate of the extent to which each need is uniquely satisfied over and above that global level (i.e., expressed as deviations, or imbalances, from the global level). Research in which these two layers of measurement remain confounded is thus likely to lead to an unduly similar assessment of the relative contribution of all three needs due to the impact of the unmodeled global component underpinning these ratings (Gillet, Morin, Huart et al., 2019; Sánchez-Oliva et al., 2017), making it impossible to rigorously assess the unique contribution of each specific need. The present research seeks to address this limitation by properly distinguishing these two layers of measurement.

\section{Need Satisfaction Profiles}

The studies reviewed thus far relied on variable-centered analyses, which examine relations among variables, ignoring the possible existence of subpopulations among which these relations could differ. Tests of interactions allow for the analysis of variations in the effects of one variable as a function of another. However, variable-centered analyses still consider that this interactive effect equally apply to all participants. In contrast, person-centered analyses seek to identify qualitatively distinct subgroups characterized by different need satisfaction configurations (Meyer \& Morin, 2016).

When considering need satisfaction profiles, one should keep in mind that when global constructs co-exist with specific dimensions assessed from the same set of indicators, person-centered analyses need to rely on indicators allowing for a disaggregation of these global (global need satisfaction) and specific (unique satisfaction of each need, reflecting need imbalance) components (Morin, Boudrias et al., 2016, 2017; Morin \& Marsh, 2015). Failure to properly unpack these two tendencies results in profiles characterized by artificially similar levels across indicators, when a more differentiated set of results would be identified using indicators properly disaggregated to reflect these two components.

Unfortunately, few studies have relied on a proper disaggregation of these two layers to analyze need satisfaction from a person-centered perspective. Recent research conducted in the education (Gillet, Morin, Huyghebaert-Zouaghi et al., 2019) and general life (Tóth-Király, Bőthe, Orosz, \& Rigó, 2018) domains offered initial evidence of need satisfaction profiles based on indicators allowing for a proper disaggregation of global and specific components. Yet, this area remains to be further explored, particularly in the work domain where, to the best of our knowledge, a single study adopted this approach (Gillet, Morin, Choisay, \& Fouquereau, 2019). More precisely, this study identified four distinct need satisfaction profiles and demonstrated the replication of these profiles across two distinct samples of employees (1- soldiers; 2- workers from a variety of industries). In addition to showing relations between these profiles and a series of job demands and resources, authors also revealed that 
levels of anxiety and physical fatigue were the lowest in a profile characterized by average levels of need satisfaction across all indicators, thus supporting the benefits of balance.

\section{The Present Research \\ Toward an Identification of Nurses' Need Satisfaction Profiles}

The present study first seeks to replicate these earlier results among a sample of nurses. Nursing is known to be a very demanding occupation (Pisanti, van der Doef, Maes, Lazzari, \& Bertini, 2011), where inadequate staffing and resources combine with austerity measures to lead nurses to make generally poor ratings of their work environments (Aiken, Sloane, Bruyneel, Van den Heede, \& Sermeus, 2013). Other specificities of the nursing profession, including confrontation with death and suffering or shift work (Pisanti et al., 2011), make the nursing context very distinctive, and may thus lead to distinct need satisfaction profiles. Despite it being difficult to generalize earlier results obtained in a single study, to a very distinct sample of nurses, previous results from Gillet, Morin, Choisay, and Fouquereau's (2019) study, coupled with the above-mentioned variable-centered results and theoretical developments allow us to formulate the following hypotheses:

Hypothesis 1. A relatively small (3 to 5) number of profiles will be identified.

Hypothesis 2. At least one large Normative profile, characterized by average balanced levels of need satisfaction, should be identified.

Hypothesis 3. Profiles characterized by high levels of global need satisfaction will display a balanced (i.e., close to average) level of specific need satisfaction, whereas profiles characterized by lower levels of global need satisfaction will show more imbalance (i.e., showing higher or lower levels relative to the sample mean) in specific levels of need satisfaction ${ }^{1}$.

\section{Longitudinal Similarity and Stability}

Our second objective is to extend Gillet, Morin, Choisay, and Fouquereau's (2019) results via the adoption of a longitudinal perspective, allowing us to assess the extent to which the identified profiles, and membership into these profiles, would be similar and stable over a three-month period. In line with prior research (Huyghebaert, Gillet, Fernet, Lahiani, Chevalier et al., 2018), we expected this specific time lag to be suitable because it goes beyond daily fluctuations (e.g., Bakker \& Oerlemans, 2019) but it is still short enough to capture changes that could not be reflected in longer time spans (e.g., Trépanier et al., 2016). An important prerequisite to being able to rely on person-centered results to guide interventions tailored at distinct profiles of employees is the demonstration that the results do not reflect ephemeral fluctuations but tap into relatively stable inter-individual differences that will remain unchanged in the absence of intervention or change (Meyer \& Morin, 2016). When considering longitudinal stability, person-centered research differentiates two forms of stability: Within-sample stability (or similarity) and within-person stability (Gillet, Morin, \& Reeve, 2017; Kam et al., 2016).

Within-sample stability, or similarity, refers to the identification of a similar number (i.e., configural similarity) of profiles characterized by the same shape (i.e., structural similarity) over time. These two types of within-sample stability are the most crucial for practical purposes. Should the nature of the profiles be found to change almost randomly over time, especially over relatively short periods of time, this would indicate that the profiles fail to identify inter-individual differences in a way that can be fruitfully used to guide interventions. Within-sample stability also involves verifying the degree to which members of specific profiles remain similar to one another over time (i.e., dispersion similarity), and whether the size of the profiles (i.e., distributional similarity) remains unchanged. Although finding support of dispersion and distributional similarity reinforces the idea that the profiles reflect some meaningful configuration of employees' characteristics, these two types of within-sample stability are not as critical, and observing changes at this level can even suggest that these configurations might be easier to modify by way of targeted intervention strategies.

In contrast, within-person stability refers to how stable employees' membership into specific

\footnotetext{
${ }^{1}$ No formal guideline exists, or should exist, to guide the interpretation of what represents high or low levels on profile indicators, given that profiles should be interpreted holistically based on the overall configuration of indicators. We note, however, that the approach used in the present study allows us to estimate latent profiles using indicators measured in standardized units (i.e., with a mean of 0 and an SD of 1). This means that profilespecific levels on each indicator are already expressed in an "effect size metric" as a deviation from the mean expressed in SD units. In this context, we tentatively consider deviations higher than .25 SD to be meaningful, but reinforce that this interpretation remains subjective, and not necessary to the interpretation of latent profiles.
} 
profiles remains over time (Kam et al., 2016). This form of (in)stability is independent from withinsample stability. For instance, noting that the global level of need satisfaction decreases over time can be translated into: (a) changes in the nature of the profiles so that they come to display higher global levels of need satisfaction (a lack of within-sample structural stability); (b) a relative growth in the size of profiles characterized by higher global levels of need satisfaction (a lack of within-sample distributional stability); or (c) a more pronounced tendency for employees to transition to profiles presenting higher global levels of need satisfaction (a lack of within-person stability).

So far, research on need satisfaction profiles in the work context has been cross-sectional. Yet, it is interesting to note that Gillet, Morin, Choisay and Fouquereau (2019) found evidence of betweensample similarity (configural, structural, and distributional, but not dispersion) across samples. Moreover, results from person-centered research conducted in the educational domain revealed that need satisfaction profiles displayed high levels of within-sample similarity, coupled with moderate to high levels of within-person stability for most profiles, over a ten-week period (Gillet, Morin, Huyghebaert-Zouaghi et al., 2019). A few person-centered studies of need satisfaction trajectories (calculated on one need at a time), also observed moderate levels of longitudinal stability in need satisfaction among samples of students (Gillet, Morin, Huyghebaert et al., 2019; Ratelle \& Duchesne, 2014) or employees (De Gieter, Hofmans, \& Bakker, 2018). Similarly, a variable-centered longitudinal study of employees' need satisfaction revealed a moderately high level of stability in ratings over three-month (Huyghebaert, Gillet, Fernet, Lahiani, Chevalier et al., 2018).

Hypothesis 4. At the within-sample level, results will support the configural, structural, and distributional similarity of the profiles.

Hypothesis 5. Profiles will display a moderate to high level ${ }^{2}$ of within-person stability. Individual Orientations and Need Satisfaction Profiles

A third aim of the present study is to assess how individual characteristics (i.e., perfectionism) and individually-driven orientations (i.e., job crafting) predict membership into need satisfaction profiles, rather than focusing on a set of indirectly measured (i.e., employees' perceptions) job characteristics (Gillet, Morin, Choisay, \& Fouquereau, 2019). When considering perfectionism, a key distinction that appears critical to consider is the one between the endorsement of perfectionistic standards, and the experience of perfectionistic discrepancies in relation to those standards (Stoeber \& Otto, 2006). Perfectionistic standards refer to employees' self-imposed strivings toward perfection, and can be considered to represent a bright side of perfectionism as they have generally been found to predict beneficial outcomes (e.g., Childs \& Stoeber, 2010; Mitchelson, 2009; Tziner \& Tanami, 2013). Conversely, perfectionistic discrepancies reflect one's concerns about not being able to live up to their own expectations, and can be considered to represent a darker side of perfectionism, found to predict adverse consequences (Kazemi \& Ziaaddeni, 2014; Ozbilir, Day, \& Catano, 2015).

Because need satisfaction is critical to employees' adaptive functioning (Deci \& Ryan, 2000), it seems appropriate to presume that perfectionistic standards and discrepancies would respectively positively and negatively relate to need satisfaction. Indeed, individuals with high perfectionistic standards tend to present higher levels of social connection (i.e., high relatedness; Rice, Leever, Christopher, \& Porter, 2006), to set and pursue more challenging goals (i.e., high autonomy), and to strive for self-improvement (Hewitt \& Flett, 1991) which is likely to enhance their self-efficacy (i.e., high competence; Bandura, 1997). In contrast, employees with high perfectionistic discrepancies tend to be socially disconnected (i.e., low relatedness; Rice et al., 2006), driven by negative pressures (i.e., low autonomy; Gaudreau \& Thompson, 2010), and to feel inadequate (i.e., low competence; Rice, Lopez, \& Richardson, 2013). No research has yet considered the relations between these two facets of perfectionism and employees' need satisfaction profiles, yet variable-centered results have generally

\footnotetext{
${ }^{2}$ No formal guideline exists, or should exist, to guide the interpretation of what represents high, low, or moderate rates of stability. To some extent, these interpretations will always have to vary from one study to the other depending on the time interval, but also on the relative stability of all profiles. As a very rough guideline, considering the fact that the present study relies on a relatively short time interval ( 3 months) and on a construct that is known to fluctuate moderately over time (i.e., need satisfaction) we tentatively suggest rates of stability close to $50 \%$ or higher to reflect moderate levels of stability, and rates close to $70 \%$ or higher to reflect high levels of stability. We caution readers, however, about blindly adopting such guidelines, and reinforce that we do not see such guidelines as necessary to the interpretation of latent transition analyses.
} 
demonstrated positive relations between perfectionistic standards and psychological need satisfaction, and negative relations between perfectionistic discrepancies and need satisfaction in different contexts (Boone, Vansteenkiste, Soenens, Van der Kaap-Deeder, \& Verstuyf, 2014; Jowett, Hill, Hall, \& Curran, 2016). Moreover, results from a person-centered study conducted in the educational context and based on another, yet similar in its bright versus dark facets, conceptualization of perfectionism (Gillet, Morin, Huyghebaert-Zouaghi, et al., 2019) corroborate these expected associations.

Hypothesis 6. Perfectionistic standards should predict membership into profiles characterized by high levels of need satisfaction and more balanced need satisfaction levels.

Hypothesis 7. Perfectionistic discrepancies should predict membership into profiles characterized by low levels of need satisfaction and more imbalanced need satisfaction levels.

Job crafting occurs when employees proactively change aspects of their job to improve the fit between the characteristics of the job and their own needs, abilities, and preferences (Tims, Bakker, \& Derks, 2012). Recent research has proposed that job crafting could be seen as encompassing three distinct dimensions (Harju, Hakanen, \& Schaufeli, 2015; Rudolph, Katz, Lavigne, \& Zacher, 2017; van Wingerden, Bakker, \& Derks, 2017): (1) increasing social job resources (e.g., seeking social support from peers); (2) increasing structural job resources (e.g., creating opportunities to develop one's professional skills); (3) increasing challenging job demands (e.g., initiating a new project). Job crafting represents a logical antecedent of employee need satisfaction. First, when employees increase their social resources, they modify their social environment in a proactive way (autonomy), create more opportunities for constructive feedback (competence), and connect with their peers (relatedness). Second, when they increase their structural resources, employees gain control over their job (autonomy), may reach out to others to find ways to develop themselves (relatedness), and become able to better develop and use their capacities (competence). Third, when they increase the challenging demands of their job, employees decide how to set and pursue these new goals (autonomy), may start new projects through which they use their full potential (competence), and are likely to feel valued and appreciated for taking on these new projects (relatedness). Variable-centered studies have supported the idea that employees who rely more importantly on job crafting experience higher levels of need satisfaction (Slemp \& Vella-Brodrick, 2014; van Wingerden et al., 2017).

Hypothesis 8 . Job crafting should predict membership into profiles characterized by high levels of need satisfaction and more balanced need satisfaction levels.

\section{Individual Outcomes of Need Satisfaction Profiles}

Our final objective is to document the implications of need satisfaction profiles for individual functioning. Specifically, we consider outcomes allowing for a more complete understanding of individual functioning (Keyes, 2005), covering both positive (vigor and job satisfaction) and negative aspects (need for recovery), rather than just the latter (Gillet, Morin, Choisay, \& Fouquereau, 2019).

Vigor is considered to be the core component of work engagement (van den Broeck, Vansteenkiste, De Witte, \& Lens, 2008) and refers to the willingness to invest effort in one's work, along with demonstrating persistence, energy, and mental resilience while working. When exposed to a job that contributes to their self-realization (Deci \& Ryan, 2008), in part by making them feel more independent, efficient, and appreciated, employees have been shown to feel more energized and vigorous at work (Gillet, Fouquereau, Huyghebaert, \& Colombat, 2015; Huyghebaert, Gillet, Lahiani et al., 2018; Trépanier, Fernet et al., 2015; van den Broeck et al., 2008).

Hypothesis 9. Membership into profiles characterized by high and balanced levels of need satisfaction should be accompanied by higher levels of vigor than membership into profiles characterized by low and imbalanced levels of need satisfaction.

To remain vigorous, employees also need to recover from their work-related efforts (Sonnentag \& Fritz, 2007). Yet, they do not always find opportunities to efficiently recover from work when they go home at night, leading to a need for recovery (Sonnentag et al., 2010). Need for recovery "is characterized by temporary feelings of overload, irritability, social withdrawal, lack of energy for new effort and reduced performance" (Van Veldhoven \& Broersen, 2003, p. i3). This is an issue for organizations as employees with a high need for recovery often go back to work in a physical and emotional state that does not allow them to perform well (Sonnentag, 2012). To our knowledge, need satisfaction was never explored in relation to need for recovery. Yet, it seems plausible that when employees do not feel volitional, useful, or appreciated, they may expand more efforts to cope with these negative experiences, and even ruminate more about these experiences outside of the work 
setting, thus increasing their need for recovery. In addition, at high levels, need for recovery gradually turns into more serious difficulties, such as burnout (van Veldhoven \& Broersen, 2003), which itself shares clear relations with low levels of need satisfaction (Huyghebaert, Gillet, Lahiani et al., 2018).

Hypothesis 10. Membership into profiles characterized by low and imbalanced levels of need satisfaction should be accompanied by higher levels of need for recovery than profiles characterized by high and balanced need satisfaction levels.

Because of its negative relations with turnover intentions and other outcomes, employees' job satisfaction is a crucial element to consider for organizations (e.g., Freund, 2005). Locke (1976, p. 1304) defines job satisfaction as "a pleasurable or positive emotional state resulting from the appraisal of one's job or job experiences". SDT suggests that when employees' psychological needs are satisfied at work, they are more likely to enjoy their tasks and experience job satisfaction (Ilardi, Leone, Kasser, \& Ryan, 1993). Thus, in a work environment allowing them to feel independent, efficient, and appreciated, employees are provided with psychological resources that promote their personal development and optimal functioning (Deci \& Ryan, 2008) and may thus have a positive evaluation of their work experience. Variable-centered research has indeed shown positive relations between need satisfaction and job satisfaction (e.g., Hetland et al., 2015; Huyghebaert, Gillet, Fernet, Lahiani, Chevalier et al., 2018; Vansteenkiste et al., 2007).

Hypothesis 11. Membership into profiles characterized by high and balanced levels of need satisfaction should be accompanied by higher levels of job satisfaction than membership into profiles characterized by low and imbalanced levels of need satisfaction.

\section{Participants and Procedure}

Materials and Methods

This study relied on a sample of 1319 nurses $\left(M_{\text {age }}=41.10 ; S D=11.11\right)$ working in healthcare centers located in France. Among participants, 1156 were women (87.60\%), 147 were men $(11.10 \%)$ and 16 did not specify their gender (1.20\%). Participants were asked to complete a questionnaire at two time points, separated by a three-month period. Of the 1319 participants, $365(27.7 \%)$ completed the questionnaire at both data collection times and 954 (72.3\%) completed only Time 1 or Time 2. According to local regulations, no formal ethical scrutiny was required as no ethics committee existed in the institution at the time of the study ${ }^{3}$. However, healthcare centers had previously agreed to take part in the study and participation was based on informed consent, after a meticulous explanation of the research's purpose. At each data collection time, nurses were reminded that participation was voluntary and that their responses would remain anonymous thanks to the use of an identification code allowing to match their responses at both data collection points. Questionnaires were returned either through sealed boxes or through pre-stamped envelopes addressed to the research team.

\section{Measures}

All measures were administered in French. Instruments that were not already available in this language were adapted using a standard translation back-translation method (e.g., Beaton et al., 2000). Participants who participated at each time wave left very few missing responses $(0 \%$ to $0.90 \%)$.

Need satisfaction. Need satisfaction was measured using nine items from a scale originally developed in French by Gillet, Rosnet, and Vallerand (2008), which were here contextualized with the sentence "At work ...". Participants were asked to rate on a 7-point scale ranging from 1 (strongly disagree) to 7 (strongly agree) the extent to which they experienced the described situations. Three items referred to the need for competence (e.g., "I feel like I am able to meet the demands of the tasks that I have to perform"; Time $1 \alpha^{4}=.71$; Time $2 \alpha=.73$ ), three items measured the need for autonomy (e.g., "I have the opportunity to make decisions about the tasks that I have to perform"; Time $1 \alpha=$ .64; Time $2 \alpha=.78$ ), and three items assessed the need for relatedness (e.g., "I get along well with the people whom I interact with"; Time $1 \alpha=.70$; Time $2 \alpha=.60$ ). Previous studies showed good

\footnotetext{
${ }^{3}$ This study was therefore not preregistered in an independent, institutional registry

${ }^{4}$ Although we report scale score reliability estimates based on Cronbach alpha $(\alpha)$ associated with each of our measures in this section, more precise model based composite reliability coefficients (Dunn, Baguley, \& Brunsden, 2014; Morin, Myers, $\&$ Lee, 2019) are reported in the preliminary analysis section. These coefficients were calculated as McDonald's (1970) omega $(\omega)$ coefficient from the absolute values of the standardized factors loadings $\left(\left|\lambda_{i}\right|\right)$ and the standardized item uniquenesses $(\delta i)$ taken from preliminary measurement models as:
}

$$
\omega=\frac{\left(\sum\left|\lambda_{i}\right|\right)^{2}}{\left[\left(\sum\left|\lambda_{i}\right|\right)^{2}+\sum \delta_{i}\right]}
$$


psychometric properties for this 9-item scale adapted to the work setting (e.g., Gillet et al., 2015).

Perfectionism (Predictor). We used the Short Almost Perfect Scale (SAPS; Rice, Richardson, \& Tueller, 2014) to assess participants' levels of perfectionistic standards (4 items; e.g., "I have strong expectations for myself"; Time $1 \alpha=.82$; Time $2 \alpha=.86$ ) and perfectionistic discrepancies (4 items; e.g., "I often feel disappointment after completing a task because I know I could have done better"; Time $1 \alpha=.82$; Time $2 \alpha=.84$ ). Responses were provided on a 7-point Likert-type scale ranging from 1 (strongly disagree) to 7 (strongly agree).

Job crafting (Predictor). We assessed job crafting through three subscales from the Job Crafting Scale (JCS; Tims et al., 2012). Each of the increasing social resources (e.g., "I ask colleagues for advice"; Time $1 \alpha=.69$; Time $2 \alpha=.73$ ), increasing structural resources (e.g., "I try to develop my capabilities"; Time $1 \alpha=.61$; Time $2 \alpha=.68$ ) and increasing challenging job demands (e.g., "I regularly take on extra tasks even though I do not receive extra salary for them"; Time $1 \alpha=.70$; Time $2 \alpha=$.72) subscales consisted of five items. Participants indicated their responses on a five-point scale ranging from 1 (never) to 5 (very often).

Vigor (Outcome). We assessed vigor with a 3-item subscale (e.g., "At my work, I feel bursting with energy"; Time $1 \alpha=.84$; Time $2 \alpha=.85$ ) from the short version of the Utrecht Work Engagement Scale (UWES; Schaufeli, Bakker, \& Salanova, 2006). Responses were indicated on a 7-point scale ranging from 1 (never) to 7 (always).

Need for recovery (Outcome). We used the 5-item short form (Sonnentag et al., 2010) of the need for recovery scale (van Veldhoven \& Broersen, 2003). Participants indicated on a scale ranging from 1 (never) to 4 (always) how often they experienced the described states (e.g. "Often, after a day's work I feel so tired that I cannot get involved in other activities"; Time $1 \alpha=.80$; Time $2 \alpha=.81$ ).

Job Satisfaction (Outcome). We measured job satisfaction with a single item (i.e., "Overall, how satisfied are you with your job"). Participants indicated their responses on a 7-point scale ranging from 1 (very unsatisfied) to 7 (very satisfied). Prior research has demonstrated that a single item measure was an inclusive and valid measure of general job satisfaction (Wanous, Reichers, \& Hudy, 1997).

\section{Analyses}

\section{Preliminary Analyses}

Preliminary factor analyses were conducted using Mplus 7.4 (Muthén \& Muthén, 2015) to verify the psychometric properties of all measures. Factor scores (estimated in standardized units with $M=0$, $S D=1$ ) from these preliminary models were used as inputs for the main analyses. To ensure comparability in the measures across time waves, these factors scores were saved from longitudinally invariant measurement models (Millsap, 2011). Although factor scores do not explicitly control for measurement errors the way latent variables do, they do provide a partial control for measurement errors by giving more weight to items presenting lower levels of measurement errors (Skrondal \& Laake, 2001). Factors scores also preserve the nature of the underlying measurement structure (e.g., measurement invariance) better than scale scores (for a more extensive discussion of the advantages of factor scores in the estimation of latent profile analyses (LPA; see Morin, Boudrias et al., 2016; Morin, Meyer, Creusier, \& Biétry, 2016). Details on these models, their longitudinal invariance, and correlations among variables are reported in the online supplements. As shown in these supplements, composite reliability estimates for the multi-item predictors and outcomes proved to be equivalent across time points and equally satisfactory: Vigor $\omega=.853$; need for recovery $\omega=.803$; perfectionistic standards $\omega=.844$; perfectionistic discrepancies $\omega=.812$; increasing structural resources $\omega=.797$; increasing social resources $\omega=.717$; and increasing challenging demands $\omega=.585$.

The measurement models for the need satisfaction variables were estimated using bifactor exploratory structural equation modeling (ESEM) (Morin, Marsh, \& Nagengast, 2013). This decision is based on recent evidence showing that a bifactor-ESEM representation (illustrated in Figure S1 of the online supplements) is well-suited to measures of need satisfaction at work (Gillet, Morin, Choisay, \& Fouquereau, 2019; Gillet, Morin, Huart et al., 2019; Sánchez-Oliva et al., 2017), and in other contexts (Garn et al., 2018; Tóth-Király, Morin et al., 2018). This representation results in a direct estimate of the global level of need satisfaction across all three needs, coupled with a direct estimate of the specificities (or imbalance) remaining in each of the specific needs. In these bifactor models, all need satisfaction items associated with the three subscales were used to define an overarching global factor (G-factor) reflecting participants' global need satisfaction. In addition, all subscale-specific items were used to define a S-factor reflecting the unique variance associated with 
each need left unexplained by the G-factor (i.e., expressed as deviations from the global level).

As noted in the online supplements, this model resulted in a well-defined global need satisfaction factor, and of specific need satisfaction factors retaining some levels of additional specificity for autonomy and relatedness. However, these results showed that, once the variance explained by global need satisfaction was considered, no meaningful specificity remained located at the level of the specific competence factor. As noted in the online supplements, this result was expected, and suggested that, among this specific sample (i.e., nurses), levels of satisfaction of the need for competence were systematically found to be in perfect balance with that of the other needs. As such, profiles were then estimated based on factor scores reflecting global need satisfaction (defined by all autonomy, competence, and relatedness items), specific autonomy satisfaction (defined from the autonomy items as the variance in autonomy need satisfaction left unexplained by the G-factor), and specific relatedness satisfaction (defined from the relatedness items as the variance in relatedness need satisfaction left unexplained by the G-factor). Although factor scores related to the specific competence satisfaction (defined from the competence items as the variance in competence need satisfaction left unexplained by the G-factor) were also saved as part of this process, they were simply not used in the following analyses due to very low levels of residual specificity.

\section{Main Model Estimation Procedures}

Models were estimated using Mplus 7.4 (Muthén \& Muthén, 2015) robust maximum likelihood estimator (MLR) and Full Information Maximum Likelihood (FIML) to handle missing data (Enders, 2010; Graham, 2009). FIML allowed us to estimate all models using data from all respondents who completed one wave of data $(\mathrm{N}=1319)$ rather than using a problematic quasi-listwise deletion strategy focusing on those having answered both time waves $(\mathrm{N}=365)$. FIML has comparable efficacy to multiple imputation, while being more efficient (Enders, 2010; Graham, 2009; Jeličič, Phelps, \& Lerner, 2009; Larsen, 2011). We note that FIML relies on missing at random (MAR) assumptions, so that it is robust to the presence of difference between participants related to attrition, as it allows the missing response process to be conditioned on all variables included in the model.

\section{Time-Specific Latent Profile Analyses (LPA)}

LPA are explicitly designed to estimate latent subpopulations, referred to as profiles, of participants presenting a qualitatively and quantitatively distinct configuration on a series of indicators (here, the global and specific need satisfaction variables) (Morin \& Litalien, 2019). LPA were first estimated separately at each time point using the three need satisfaction factors as indicators to verify whether the same number of profiles would be extracted at each time point. We examined time-specific solutions including 1 to 8 latent profiles in which the means and variances of the need satisfaction factors were allowed to differ across all profiles (Diallo, Morin \& Lu, 2016; Morin et al., 2011; Peugh \& Fan, 2013). All LPA were estimated with 5000 random sets of start values, 1000 iterations, and the 200 best solutions retained for final optimization (Hipp \& Bauer, 2006; McLachlan \& Peel, 2000). These values were increased to 10000,2000 , and 500 for the longitudinal models.

To help deciding on the optimal number of profiles, we considered the theoretical conformity and meaningfulness, as well as the statistical adequacy of the alternative solutions (Bauer \& Curran, 2003; Marsh, Lüdtke, Trautwein, \& Morin, 2009; Muthén, 2003). We also considered a series of statistical indices to help guide this decision (McLachlan \& Peel, 2000): (i) the Akaïke Information Criterion (AIC), (ii) the Consistent AIC (CAIC), (iii) the Bayesian Information Criterion (BIC), (iv) the samplesize Adjusted BIC (ABIC), (v) the adjusted Lo, Mendel and Rubin's (2001) Likelihood Ratio Tests, and (iv) the Bootstrap Likelihood Ratio Test (BLRT). Lower AIC, CAIC, BIC, and ABIC values suggests a better-fitting model. A statistically significant aLMR or BLRT supports the estimated model when compared to a model including one less profile. Simulation studies support the efficacy of the CAIC, BIC, ABIC, and BLRT, but not that of the AIC and aLMR (Diallo et al., 2016, 2017; Henson, Reise, \& Kim, 2007; Nylund, Asparouhov, \& Muthén 2007; Peugh \& Fan, 2013; Tein, Coxe, \& Cham, 2013; Tofighi \& Enders, 2008; Yang, 2006). For this reason, the AIC and aLMR are only reported to ensure complete disclosure, but will not be used to select the optimal number of profiles. In addition, because these tests all remain influenced by sample size (Marsh et al., 2009), they often keep on suggesting the addition of profiles without reaching a minimum. When this happens, the point at which the decrease in the value of these indicators reaches a plateau, on a graphical display (i.e., an elbow plot), can be used to suggest the optimal solution (Morin et al., 2011). Finally, the entropy (ranging from 0 to 1 ) indicates the precision with which the cases are classified into the various 
profiles, but should not be used to guide model selection (Lubke \& Muthén, 2007).

\section{Tests of Profile Similarity}

Once the optimal number of profiles had been selected at each specific time point, we integrated the two retained LPA solutions (one at each time point) into a single longitudinal LPA model allowing for systematic longitudinal tests of profile similarity. In this longitudinal model, two specific LPA solutions (one per time point) were thus jointly considered, but specified as simply independent from one another (which is similar to allowing two latent constructs to correlate with one another), rather than specifying Time 2 profiles as conditional on (i.e., predicted by, or regressed on) Time 1 profiles. These tests were conducted following the sequential strategy proposed by Morin, Meyer et al. (2016) for tests of profile similarity across multiple groups and optimized by Morin and Litalien (2017) for longitudinal comparisons. The first step examines whether the same number of profiles can be identified at each time point (i.e., configural similarity) and corresponds to the previously described time-specific LPA. In the second step, the structural similarity of the profiles is verified by including equality constraints across time points on the means of the profile indicators to test whether the profiles retain the same global shape over time. The third step tests the dispersion similarity of the profiles by including equality constraints across time points on the variances of the profile indicators to verify whether the within-profile variability remains stable across time points. The fourth step tests the distributional similarity of the profiles by constraining the class probabilities to equality across time points to ascertain whether the relative size of the profiles remains the same over time. The fit of these models can be compared using the information criteria, and Morin, Meyer et al. (2016) suggest that at least two indices out of the CAIC, BIC, and ABIC should be lower for the more "similar" model for the hypothesis of profile similarity to be supported.

\section{Latent Transition Analyses}

The most similar model from the previous sequence was then converted to a longitudinal Latent Transition Analysis model (LTA; Collins \& Lanza, 2010; Nylund et al., 2007), to investigate withinperson stability and transitions in profile membership (Morin \& Litalien, 2017). This LTA model differs from the previously described longitudinal LPA solution only in that Time 2 profiles are now specified as conditional on (i.e., predicted by, or regressed on) Time 1 profiles. This sequence was then extended to tests of predictive and explanatory similarity to investigate whether the associations between the profiles and, respectively, their predictors and outcomes remained the same across time points. Following Morin and Litalien's (2017) recommendations, all LTA were estimated using the manual auxiliary 3-step approach described by Asparouhov and Muthén (2014). This approach made it possible to ensure that all analyses reported in this study rely on the estimation of "latent" probabilitybased profiles in which each participant had a probability of membership in all profiles, corresponding to some forms of measurement error in the assignment of participants into prototypical profiles (e.g., Morin, Bujacz, \& Gagné, 2018), which was controlled for in all analyses.

Auxiliary approaches are used to re-express a probabilistic LPA while ensuring a greater level of stability when facing additional constraints and covariate inclusion. In the present context, the approach for tests of profile similarity proposed by Morin, Meyer et al. (2016) provides a way to test the similarity of the profile probabilities (distributional similarity) across time points in a longitudinal LPA, but not in the context of a LTA. Indeed, in LTA, this approach would involve constraining the "intercepts" of the Time 2 profile probabilities, as predicted by the Time 1 profiles, to equality. In contrast, the manual implementation of the auxiliary 3-step approach proposed by Morin and Litalien (2017) provides a way to estimate transitions from a model of distributional similarity, while also ensuring greater stability to covariate inclusion. Essentially, this approach relies on the class probabilities obtained from the final model of distributional similarity (step 1), which are then used as nominal profile indicators in the estimation of a new latent profile solution in which classification logits are used to retain a probability-based classification (step 2). This new solution is then used in further analyses (step 3). For additional details, and technical implementation, see Morin and Litalien (2017), Asparouhov and Muthén (2014), and McLarnon and O’Neill (2018).

\section{Predictors}

Multinomial logistic regressions were used to test the relations between the predictors (perfectionistic standards, perfectionistic discrepancies, increasing structural resources, increasing social resources, and increasing challenging demands) and profile membership. In these analyses, the predictors were directly integrated into the LTA model and used to predict the likelihood of profile 
membership. In these models, time-specific measures of perfectionism and job crafting were allowed to predict latent profile membership at the matching time point. Three alternative models were contrasted (Ciarrochi, Morin, Sahdra, Litalien, \& Parker, 2017; Gillet, Morin, Huyghebaert et al., 2019). First, the relations between the predictors and the profiles were freely estimated across time points and predictions of the profiles estimated at a specific time point were allowed to vary across the profiles estimated at the previous time point. Essentially, this model provides a direct test of the effects of the predictors on profile transitions (i.e., on the likelihood of transitioning into a specific profile at the next time point based on profile membership at the prior time point). Second, predictions were freely estimated across time, but not profiles. In this model, the predictors were not allowed to predict profile transitions, but their effects were allowed to change over time. Finally, the predictive similarity of the model was tested by constraining predictions to equality over time.

\section{Outcomes}

Outcomes were also incorporated into the final LTA solution. Time-specific measures of outcomes (vigor, need for recovery, and job satisfaction) were specified as associated with the latent profiles estimated at the matching time point. We then proceeded to tests of explanatory similarity by constraining the within-profile means of these outcomes to equality across time points. Given the complexity of the models estimated here, it was not possible to simultaneously integrate predictors and outcomes in the same model. Thus, predictors and outcomes were separately integrated (in two distinct analyses) in the final model of profile similarity. Yet, all of these models simultaneously included predictor or outcome measures taken at both time points, so that the effects of Time 2 predictors can be considered to be controlled for Time 1 predictor measures, and the effects of profile membership on Time 2 outcomes can also be considered to be controlled for Time 1 outcome measures. The Mplus' MODEL CONSTRAINT command was used to test mean-level differences across pairs of profiles using the multivariate delta method (Kam et al., 2016; Raykov \& Marcoulides, 2004).

\section{Further Information}

The analyses used in the present study are complex, and might not be easy to understand and replicate for interested readers. To support this endeavor, we first provide a figural representation of the theoretical model tested in the present study in Figure 1. We also refer readers interested in learning how to estimate most models (LPA, longitudinal tests of profile similarity, and LTA with predictors and outcomes) to consult Morin and Litalien's (2019) user friendly introduction to mixture modeling. Those specifically interested in the combination of bifactor-ESEM and LPA should also consult Morin, Boudrias et al. (2017). In contrast, readers seeking a more technical (or mathematical) introduction to these models should consult McLachlan and Peel (2000), Skrondal and Rabe-Hesketh (2004), or Collins and Lanza (2010, for a coverage more specific to LTA).

\section{Results}

The fit indices associated with the time-specific LPA are reported in Table 1 (elbow plots are reported in Figures S2 and S3 of the online supplements). Across time waves, most statistical indicators keep on suggesting the addition of profiles without converging on any specific solutions, with the exception of the BIC, which reached its lowest point at six profiles at Time 1 and seven profiles at Time 2, and the CAIC, which reached its lowest point at seven profiles at Time 2.

We thus relied on elbow plots to obtain additional guidance. These plots revealed two inflection points, corresponding to the two-profile and four-profile solutions, at both time points. Solutions including two to five profiles were thus more carefully considered. Importantly, this careful examination revealed a high level of similarity in the matching solutions estimated across time points, thus already providing evidence of longitudinal similarity. Moreover, this examination revealed that up to four profiles, each increase resulted in the addition of a meaningful profile to the solution at both time points. In contrast, adding a fifth profile only resulted in the arbitrary division of an existing profile into smaller ones. On the basis of these considerations, the four-profile solution (matching the second inflection point) was retained at both time waves, supporting its configural similarity. This solution provides a reasonable level of classification accuracy, with an entropy value of .722 at Time 1 and .673 at Time 2. These results thus support Hypothesis 1 . The fit indices from the final timespecific LPA, and from the longitudinal LPA and LTA are reported in Table 2.

The results from the longitudinal LPA analyses further support the structural similarity of this solution (based on the observation of lower values on all information criteria), but not its dispersion similarity (based on the observation of higher values on all information criteria). We thus pursued a 
solution of partial dispersion similarity in which equality constraints on the within-profile variances had to be removed in three out of four profiles, but retained in the largest one. This model of partial dispersion was supported by the data (based on the observation of lower values on the CAIC, BIC, and $\mathrm{ABIC}$ relative to the model of structural similarity). It mainly revealed that levels of within-profile variability tended to slightly decrease at Time 2 , suggesting that profile members tended to become slightly more similar to one another over time. Finally, the model of distributional similarity was also supported (based on the observation of lower values on the CAIC, BIC, and ABIC) and retained for interpretation and for the next stages. This final model is illustrated in Figure 2 (within-profile means are reported in Table S5 of the online supplements). These results thus generally support Hypothesis 4 .

Profile 1 was characterized by low levels of global need satisfaction accompanied by moderately low specific levels of autonomy need satisfaction, and slightly below average levels of relatedness need satisfaction. This Globally Dissatisfied profile corresponded to $15.14 \%$ of the sample. Profile 2 presented average levels of global need satisfaction accompanied by equally average specific levels of autonomy and relatedness needs satisfaction. This Normative profile was the largest, and characterized $64.72 \%$ of the participants, thus supporting Hypothesis 2. Profile 3 presented moderately high levels of global need satisfaction accompanied by close to average specific levels of autonomy and relatedness needs satisfaction. This Moderately Satisfied profile characterized $17.77 \%$ of the participants. Finally, Profile 4 presented high levels of global need satisfaction accompanied by average specific levels of autonomy and relatedness needs satisfaction. This "Globally Satisfied" profile characterized $2.36 \%$ of the participants. By showing that evidence of need imbalance (i.e., specific levels of need satisfaction deviating from the average) is limited to the Globally Dissatisfied profile, these results generally support Hypothesis 3 .

\section{Latent Transitions}

This final model of distributional similarity was converted to a LTA using the manual auxiliary 3step approach (Asparouhov \& Muthén, 2014; Morin \& Litalien, 2017). The transition probabilities from this LTA are reported in Table 3. These results show that membership into Profiles 1 (Globally Dissatisfied; stability of 97.9\%), 2 (Normative; stability of 100\%), and 3 (Moderately Satisfied; stability of $91.8 \%$ ) was almost perfectly stable over time. Not surprisingly, transitions were rare for participants initially corresponding to these profiles. In contrast, membership into Profile 4 (Globally Satisfied; stability of $12.2 \%$ ) displayed a high level of instability over time. When transitions occurred for initial members of this profile, they mainly involve Profile 3 (Moderately Satisfied; 85.0\%), although some members of Profile 4 also transition to Profile 1 (Globally Dissatisfied; 2.7\%). These results thus only partially support Hypothesis 5 .

\section{Predictors of Profile Membership (Predictive Similarity)}

Before proceeding to the integration of the predictors, we investigated the need to incorporate participants' demographic characteristics (sex, tenure, work status, and employment type) as controlled variables in the upcoming analyses. As shown in Table 2, the results from the analyses involving these demographic variables supported the null effect model (which resulted in the lowest values on all information criteria), consistent with a lack of effects of demographic controls on profile membership. This conclusion was also supported by an examination of the parameter estimates associated with these models. For these reasons, demographic controls were not retained.

As shown in Table 2, when the a priori predictors were included in the model, results supported the model of predictive similarity, which resulted in the lowest BIC and ABIC values . These results support the equivalence of the predictions across time points and a lack of effects of the predictors on profile transitions. Results from this model of predictive similarity are reported in Table 4.

No statistically significant association was noted between profile membership and the increasing challenging demands dimension of job crafting, thus partially failing to support Hypothesis 8 . However, the results showed that higher levels of perfectionistic standards were associated with a lower likelihood of membership into Profiles 1 (Globally Dissatisfied), 2 (Normative), and 3 (Moderately Satisfied) relative to Profile 4 (Globally Satisfied), and into Profiles 1 (Globally Dissatisfied) and 2 (Normative) relative to Profile 3 (Moderately Satisfied). These results thus generally support Hypothesis 6. In contrast, higher levels of perfectionistic discrepancies were associated with a higher likelihood of membership into Profiles 1 (Globally Dissatisfied), 2 (Normative), and 3 (Moderately Satisfied) relative to Profile 4 (Globally Satisfied), into Profiles 1 (Globally Dissatisfied) and 2 (Normative) relative to Profile 3 (Moderately Satisfied), and into Profile 
3 (Moderately Satisfied) relative to Profile 4 (Globally Satisfied), showing an almost exactly opposite pattern of association with the profiles relative to perfectionistic standards. These results thus generally support Hypothesis 7 as they show perfectionistic discrepancies to predict membership into the profile characterized by low levels of both global and specific need satisfaction. Higher levels on the increasing structural resources dimension of job crafting were associated with a higher likelihood of membership into Profile 2 (Normative) relative to Profile 4 (Globally Satisfied), and into Profile 4 (Globally Satisfied) relative to Profile 3 (Moderately Satisfied). Finally, higher levels on the increasing social resources dimension of job crafting were associated with a lower likelihood of membership into Profile 1 (Globally Dissatisfied) relative to Profiles 3 (Moderately Satisfied) and 4 (Globally Satisfied), and into Profile 3 (Moderately Satisfied) relative to Profile 4 (Globally Satisfied). Therefore, these results generally support Hypothesis 8.

\section{Outcomes of Profile Membership (Explanatory Similarity)}

To test for explanatory similarity, outcomes were added to the LTA model of distributional similarity described earlier. We first estimated a model in which the within-profile levels of outcomes were freely estimated across time points, and contrasted this model to one in which these levels were constrained to equality across time points (i.e., explanatory similarity). As shown in Table 2, the model in which the outcome levels were constrained to equality resulted in lower values for all information criteria, thus supporting the explanatory similarity of the model. The within-profile means (and 95\% confidence intervals) of the outcomes are reported in Table 5, and illustrated in Figure 3.

These results are consistent across outcomes, generally supporting Hypotheses 9 to 11, and show that the worst outcomes (the lowest levels of vigor and job satisfaction, and the highest levels of need for recovery) are associated with Profile 1 (Globally Dissatisfied). The highest levels of vigor were observed in Profile 3 (Moderately Satisfied), followed by Profile 4 (Globally Satisfied), then by Profile 2 (Normative), and finally by Profile 1 (Globally Dissatisfied), with all pairwise comparisons being statistically significant. Profile 3 (Moderately Satisfied) was also associated with the lowest levels of need for recovery, followed equally by Profiles 2 (Normative) and 4 (Globally Satisfied) which did not differ between them, and then by Profile 1 (Globally Dissatisfied). Finally, levels of job satisfaction were the highest in Profiles 3 (Moderately Satisfied) and 4 (Globally Satisfied) which did not differ between them, followed by Profile 2 (Normative), and then by Profile 1 (Globally Dissatisfied).

\section{Discussion}

Despite the recognition of the interrelatedness of the three dimensions of psychological need satisfaction (i.e., autonomy, competence, and relatedness; e.g., Gagné, 2003), the ways in which these components are combined among specific subpopulations, or profiles, of employees has only rarely been investigated in the work context (e.g., Gillet, Morin, Choisay, \& Fouquereau, 2019). Yet, more extensive variable-centered work was recently conducted in order to better understand the complex multidimensionality associated with employees' ratings of need satisfaction. This research has resulted in an improved (bifactor) representation of need satisfaction in which global levels of need satisfaction are disaggregated from the ratings of each specific need in order to achieve a more accurate understanding of the unique, versus shared, contribution of each need (e.g., Gillet, Morin, Huart et al., 2019; Sánchez-Oliva et al., 2017). The present study was designed to extend current knowledge regarding the nature of psychological needs profiles (Huyghebaert, Gillet, Fernet, Lahiani, \& Fouquereau, 2018) among nurses, and to do so while relying on an improved bifactor representation of need satisfaction. We also sought to expand upon prior results (Gillet, Morin, Choisay, \& Fouquereau, 2019) by considering the longitudinal stability of these profiles over a period of three months, by investigating the role of individual orientations (perfectionism and job crafting) in the prediction of nurses' membership into these various profiles, and by more extensively documenting the implications of these profiles for employee functioning (vigor, need for recovery, and job satisfaction).

\section{Theoretical implications}

Supporting Hypothesis 1, results revealed the presence of four dominant need satisfaction profiles among the present sample of French nurses: (1) Globally Dissatisfied; (2) Normative; (3) Moderately Satisfied; and (4) Globally Satisfied. These profiles emphasize the importance of adopting a finergrained representation of need satisfaction by considering both the global degree to which all three needs are satisfied, and the specificity associated with each individual need over and above this global level of need satisfaction (reflecting imbalance in the satisfaction of each specific need relative to all others). In particular, and supporting Hypothesis 3, results showed that profiles characterized by low 
global levels of need satisfaction (the Globally Dissatisfied profile) tended to present a more imbalanced configuration where specific levels of need satisfaction were also lower than the sample average. In contrast, profiles showing moderate to high global levels of need satisfaction (the Normative, Moderately Satisfied, and Globally Satisfied profiles) were characterized by more balanced configurations where specific levels of need satisfaction were aligned with one another and with the sample average. In addition, the identification of a large (64.72\%) Normative profile suggests that, for the majority of the sample, global levels of need satisfaction remain satisfactory and aligned across all three needs. This result is concordant with Hypothesis 2 and with prior studies which also identified the presence of a dominant Normative profile characterized by moderate levels of well-being (Morin, Boudrias et al., 2016, 2017) or need satisfaction (Gillet, Morin, Choisay, \& Fouquereau, 2019).

When considering these results, it is also important to keep in mind that profiles were identified using three indicators respectively reflecting global levels of need satisfaction (a global factor score computed from the variance shared across all autonomy, competence, and relatedness items), as well as specific levels of autonomy and relatedness need satisfaction (specific factors reflecting what is unique to autonomy or relatedness ratings, once the variance explained by the global factor is taken into account). Indeed, preliminary analyses from which these factor scores were generated resulted in the estimation of well-defined global, specific autonomy, and specific relatedness need satisfaction factors. Yet, once the variance explained by global need satisfaction was taken into account, the competence factor was left with no meaningful specificity. This result implies that, in the present sample, ratings on the three items used to evaluate competence need satisfaction provided a much better reflection of employees' global levels of need satisfaction than of the specific need for competence. In plain language, this means that ratings of competence satisfaction were in perfect alignment with global levels of need satisfaction in the present sample. Importantly, as discussed more extensively in the online supplements, this result was not unexpected given that the identification of a "vanishing" - or at least weakly defined-S-factor appears to be the norm in prior studies in which a bifactor operationalization of need satisfaction was adopted (e.g., Garn et al., 2018; Gillet, Morin, Choisay, \& Fouquereau, 2019; Sánchez-Oliva et al., 2017). Moreover, these studies also suggest that the nature of the "vanishing" S-factor might be context-specific.

In the work context, particularly in the nursing context where nursing staff's competence is essential to provide safe, ethical, and high-quality care (Kendall-Gallagher \& Blegen, 2009) and where nurses' own recognition of their level of competence is critical in maintaining high standards of care (Blažun, Kokol, \& Vošner, 2015), it is thus not surprising to observe this high level of alignment between the ability to fully utilize their competencies, to nurture new skills and to accomplish the tasks they were trained to do in an efficient manner, and nurses' global levels of need satisfaction. Indeed, what our results show is that in this specific work context, it is nurses' feelings of being able to fully use their competencies and to rely on them that appears to be the main driver of their global levels of need satisfaction and that shows the highest levels of balance in relation to this global level.

In terms of within-sample stability, results supported Hypothesis 4 by showing that the profiles remained mainly unchanged across the three-month period considered in this study. Precisely, results revealed the same number of profiles (configural similarity), characterized by the same structure (structural similarity), the same level of within-profile variability (dispersion similarity), and the same size (distributional similarity) across measurement occasions. These observations suggest that the nature of the profiles can be expected to generalize over time among specific samples of employees.

In terms of within-person stability, our results generally supported Hypothesis 5 in revealing some within-person changes over the course of three months. Specifically, membership into three (Globally Dissatisfied, Normative, and Moderately Satisfied) of the four profiles remained highly stable over a three-month period, with stability rates ranging from $91.8 \%$ to $100.0 \%$. Though part of this stability could be due to the relatively short time lag considered in this study (i.e., three months), results also revealed important fluctuations in profile membership, which supports the idea that this time interval was sufficient to observe changes at the individual level. Indeed, membership into the Globally Satisfied profile was far more unstable over time (12.2\%), suggesting that it is more difficult to maintain such a high level of need satisfaction across all three needs over time. This result is concordant with prior research showing a decreasing tendency for students presenting the highest levels of global need satisfaction at the beginning of the semester (Gillet, Morin, Huyghebaert et al., 2019). This result is also consistent with the situational nature of need satisfaction (Vallerand, 1997), 
which is known to vary as a function of changing job characteristics (Trépanier, Forest, Fernet, \& Austin, 2015), sometimes on a daily basis (Hetland et al., 2015). When considering nursing, which is known to be a highly demanding profession carrying high risks of exhaustion and dissatisfaction (Aiken et al., 2013; Pisanti et al., 2011), this result suggests that it may be hard for nurses to maintain very high levels of global need satisfaction, and reinforces the need for organizations to implement preventive systems to help highly satisfied nurses to maintain this high level of need satisfaction.

Although prior variable-centered studies have addressed the associations between perfectionism (e.g., Boone et al., 2014; Jowett et al., 2016) or job crafting (e.g., Slemp \& Vella-Brodrick, 2014; van Wingerden et al., 2017) and psychological need satisfaction in various contexts, no research had yet been conducted to explore how these individual orientations contribute to the development of multidimensional need satisfaction profiles in the work context. Interestingly, our results showed that all of the identified associations between predictors and profiles generalized across time points.

Supporting Hypothesis 6, our results showed that higher perfectionistic standards increased the likelihood of membership into the Globally Satisfied profile relative to all other profiles, and into the Moderately Satisfied profile relative to the Globally Dissatisfied and Normative profiles. In other words, perfectionistic standards predicted membership into profiles characterized by the highest levels of global need satisfaction. This result is aligned with prior research suggesting that this facet of perfectionism tends to be adaptive (e.g., Stoeber et al., 2013). In contrast, and in accordance with Hypothesis 7, perfectionistic discrepancies showed an opposite pattern of association with the profiles, being associated with a higher likelihood of membership into the Globally Dissatisfied profile relative to all other profiles, and into the Normative profile, relative to the Globally Satisfied and the Moderately Satisfied profiles. In other words, perfectionistic discrepancies predicted membership into the profiles with the lowest levels of global need satisfaction. This result is consistent with the literature on perfectionism that depicts this facet as the dark side of perfectionism (Rice et al., 2013) due to its undesirable consequences on individual functioning (e.g., Stoeber et al., 2013).

Job crafting dimensions also showed differentiated patterns of association with the identified profiles. First, higher levels of the increasing social resources dimension were associated with a lower likelihood of membership into the Globally Dissatisfied profile relative to all other profiles. This result is consistent with the very definition of job crafting which suggests that employees proactively change aspects of their job to improve the fit between the characteristics of their job and their own needs, abilities, and preferences (Tims et al., 2012). It therefore seems logical that employees who create the conditions where their needs, abilities, and preferences can be met are the least likely to experience the lowest levels of global need satisfaction. This first result was consistent with Hypothesis 8 and with previous variable-centered findings (e.g., van Wingerden et al., 2017).

Second, higher levels of the increasing structural resources dimension of job crafting were associated with a higher likelihood of membership into the Normative profile relative to the Globally Dissatisfied and the Globally Satisfied profiles. This result thus only partially supported Hypothesis 8, suggesting that individuals who report performing behaviors aiming to increase the autonomy, skill variety, and other motivational characteristics of their job (i.e., increasing structural resources; Rudolph et al., 2017) are more likely to experience average levels of global and specific need satisfaction rather than low or high levels of global need satisfaction.

Third, higher levels of the increasing challenging demands dimension of job crafting did not significantly predict likelihood of membership in any of the identified profiles. This result differs from most of prior research (Rudolph et al., 2017) and fails to support Hypothesis 8 by showing that individuals who perform behaviors such as asking for more responsibility or volunteering for new projects (i.e., increasing challenging demands) do not undergo a significantly different psychological experience of their job. This implies that this dimension of job crafting may fail to increase the fit between employees' definitions of themselves and their work and to better individuals' perceived meaning of work. Therefore, this result contrasts with Wrzesniewski and Dutton's original work (2001) suggesting that employees engage in job crafting to fulfill their basic psychological needs for autonomy, competence, and relatedness (Deci \& Ryan, 2000). More generally, our findings further encourage researchers to look into how job crafting dimensions -rather than overall job crafting (Rudolph et al., 2017) - contribute to employees' psychological experiences.

From an outcome perspective, our results showed that the identified need satisfaction profiles displayed well-differentiated patterns of association with the various outcomes considered. These 
results revealed associations that mainly matched Hypotheses 9,10, and 11, as well as prior results (Gillet, Morin, Huart et al., 2019; Sánchez-Oliva et al., 2017; Tóth-Király, Morin et al., 2018), in supporting the role of employees' global levels of need satisfaction in the prediction of a variety of outcomes. Indeed, low levels of global need satisfaction were associated with lower levels of vigor and job satisfaction, and higher levels of need for recovery. In contrast, moderate-to-high global levels of need satisfaction were found to be associated with more desirable outcome levels. The results further showed that these associations generalized across measurement points.

More precisely, our results indicated that employees who had the lowest levels of global need satisfaction (Globally Dissatisfied) were subjected to the most maladaptive functioning (i.e., lowest levels of vigor and job satisfaction, and highest levels of need for recovery). This is in line with SDT literature showing that when individuals' psychological needs cannot be met adequately, they lack the psychological nutrients that are necessary for their well-being (Deci \& Ryan, 2000) and therefore experience adverse consequences (e.g., Huyghebaert, Gillet, Lahiani et al., 2018).

Furthermore, nurses with moderately high levels of global and specific need satisfaction (Moderately Satisfied) experienced the most optimal levels of functioning (i.e., highest levels of vigor and job satisfaction, and lowest levels of need for recovery). Precisely, nurses with moderate global levels of need satisfaction (Moderately Satisfied) experienced a better functioning than nurses with average global levels of need satisfaction (Normative). This result is in line with SDT, as it confirms that increased levels of need satisfaction contribute to the experience of heightened functioning (Deci $\&$ Ryan, 2000). However, nurses who had moderate levels of global need satisfaction (Moderately Satisfied) also experienced a better functioning than nurses who had very high levels of global need satisfaction (Globally Satisfied). This result is not concordant with SDT's premises (Deci \& Ryan, 2000). Yet, this counterintuitive result is consistent with previous results showing that the level of global need satisfaction observed in the Globally Satisfied profile mainly reflects an extreme ephemeral state proving to be hard to maintain over the long term. Therefore, rather than trying to reach extreme need satisfaction, efforts should be devoted to nurture stable and sustainable levels of need satisfaction. Overall, these differentiated effects of the Moderately Satisfied and the Globally Satisfied profiles add up to prior studies showing that the satisfaction of the specific needs have more than simple additive effects (Dysvik et al., 2013; Vansteenkiste et al., 2006) and that specific needs may exhibit differential relations with individual outcomes, depending on the context.

\section{Limitations and Directions for Future Research}

Even though it offers the first longitudinal investigation of employees' need satisfaction profiles, their predictors and outcomes, this study presents some limitations. First, we relied on self-report measures, which may have been impacted by social desirability and self-report biases. Future research could use more objective indicators of individual functioning (e.g., cardiovascular activity) together with other-rated (e.g., manager) measures of job crafting and perfectionism. Second, it should be noted that the scale we used to measure need satisfaction was not originally developed for the work context but for the sports domain (Gillet et al., 2008). Even though we contextualized this measure to the work context, in line with prior research showing good psychometric properties for this scale in this domain (Huyghebaert, Gillet, Fernet, Lahiani, Chevalier et al., 2018), it is possible that the use of context specific items could have tapped more adequately into the experience of need satisfaction at work and may have indicated different results regarding the competence specific factor. Third, additional person-centered research could extend the generalizability of the profiles, and of their associations with predictors and outcomes, across distinct samples of employees (e.g., office workers, teleworkers, managers), and in different cultures and countries (Morin, Meyer, Creusier, \& Biétry, 2016). Such evidence of generalizability would help to demonstrate the robustness of our findings and the value of implementing intervention strategies based on such person-centered results.

Fourth, in line with Meyer and Morin's (2016) recommendations, we examined covariables as either predictors (i.e., perfectionism and job crafting) or outcomes (i.e., vigor, need for recovery, job satisfaction) on the basis of a theoretical rationale drawn from prior research (e.g., van Wingerden et al., 2017). Although the approach we relied upon made it possible to rule out possible effects of predictors on profile transitions, our study design and the limitations inherent to our analytical method did not allow us to assess possible reversed causality, reciprocal influence, or spurious associations, nor the eventuality of profile transitions impacting variations in outcome levels. Therefore, future longitudinal research would gain in examining the direction of the associations among predictors, 
outcomes, and profiles. Such research could consider longer time periods to further address the issue of profile stability. Indeed, though our results showed that some within-person changes do happen over a relatively short period of time (i.e., three-months), this interval may not be sufficient to get a complete understanding of stability and changes in profile membership.

Fifth, we only looked into individual orientations (i.e., perfectionism and job crafting) as determinants of employees' need satisfaction profiles. Yet, it would be worthwhile for future research to investigate determinants that are more inherent to the work environment (e.g., climate, managerial behaviors) rather than employees' tendencies towards that environment. Moreover, our analyses revealed a weakly defined S-factor (i.e., low factor loadings, low reliability) reflecting employees' competence need satisfaction once their global levels of need satisfaction were taken into account. Even though, as previously mentioned, this is not surprising considering the importance of competence for nurses, this result did not allow to analyze latent profiles based on the entire spectrum of global and specific need satisfaction as conceived by SDT. Although this result provides support for a bifactor representation of need satisfaction (e.g., Sánchez-Oliva et al., 2017), future examinations relying on bifactor models and using different scales to measure psychological need satisfaction (e.g., van den Broeck et al., 2010) are likely to provide more information on the specificity associated with competence need satisfaction.

Finally, SDT has recently demonstrated that need satisfaction and frustration are two separate psychological experiences that have different antecedents and consequences over-time (Bartholomew, Ntoumanis, Ryan, \& Thøgersen-Ntoumani, 2011). Toth-Kiraly et al. (2018) offered a joint exploration of need satisfaction and frustration in two samples of Hungarian adults. Yet, it could be fruitful to investigate how such bifactor measurement models apply to need frustration in the work domain, and to resort to person-centered analyses to assess need frustration and satisfaction profiles, and their respective associations with work-related antecedents and employee functioning.

\section{Practical Implications}

Despite the above stated limitations, our results offer some interesting practical avenues. First and foremost, our research emphasizes that health organizations and managers would gain into avoiding low levels of global need satisfaction. Once this consideration is taken into account and once nurses are allowed to experience moderate-to-high levels of global need satisfaction in a manner that is balanced across specific need dimensions, health organizations and managers are encouraged to particularly reinforce the satisfaction of nurses need for relatedness and avoid the low satisfaction of their need for autonomy, in order to promote nurses most optimal functioning.

Our results also show that managers -though they could gain from supporting their subordinates' perfectionistic standards- ought to be particularly attentive to employees displaying high levels of perfectionistic discrepancies. Indeed, these individuals are subjected to the lowest levels of global need satisfaction which expose them to higher risks of maladaptive functioning (i.e., low vigor and job satisfaction, high need for recovery). Managers should therefore attend to their subordinates' fears and feelings, and offer them supportive and constructive feedbacks, in order to avoid such discrepancies between their standards and achievements.

Furthermore, our results provide a nuanced perspective on job crafting and imply that organizations should encourage such behaviors with caution. Indeed, the present results suggest that the proactive, bottom-up changes employees can make in terms of social or structural job resources, although they might protect them from the most adverse experiences associated with low levels of need satisfaction (i.e., Globally Dissatisfied), do not automatically guarantee the most optimal psychological experience (i.e., Moderately Satisfied). In addition, attempts to increase the challenging nature of one's job does not seem to have any impact on employees' need satisfaction levels. Our study therefore contrasts with prior research on job crafting (Rudolph et al., 2017) by showing that, although it cannot hurt, job crafting does not really help employees to secure the most optimal psychological experiences in the workplace, and may therefore not be a priority in terms of intervention. More precisely, our results suggest that these bottom-up job redesign strategies may not be the most adequate for French nurses, and may hint to more traditional top-down interventions. This does not come as a surprise as the French health industry is becoming more and more constrained and nurses may not have much leverage to redesign their job on their own, hence the limited impact of their reported job crafting on their psychological experiences. Therefore, the priority for policy makers and organizations may be to create environments that provide employees with opportunities to feel empowered and increase their 
ability to craft their job first (Petrou, Demerouti, Peeters, Schaufeli, \& Hetland, 2012), which would then make it easier for them to fully benefit from such proactive redesign strategies.

\section{References}

Aiken, L.H., Sloane, D.M., Bruyneel, L., van den Heede, K., \& Sermeus, W. (2013). Nurses' reports of working conditions and hospital quality of care in 12 countries in Europe. International Journal of Nursing Studies, 50, 143-153. doi: 10.1016/j.jinurstu.2012.11.009

Asparouhov, T., \& Muthén, B.O. (2014). Auxiliary variables in mixture modeling: Three-step approaches using Mplus. Structural Equation Modeling, 21, 1-13. doi: 10.1080/10705511.2014.915181

Bakker, A.B., \& Demerouti, E. (2017). Job demands-resources theory: Taking stock and looking forward. Journal of Occupational Health Psychology, 22, 273-285. doi: 10.1037/ocp0000056

Bakker, A. B., \& Oerlemans, W. G. (2019). Daily job crafting and momentary work engagement: A self-determination and self-regulation perspective. Journal of Vocational Behavior, 112, 417430. doi: $10.1016 /$ j.jvb.2018.12.005

Bandura, A. (1997). Self-efficacy: The exercise of control. New York, NY, USA : W H Freeman/Times Books/Henry Holt \& Co.

Bartholomew, K.J., Ntoumanis, N., Ryan, R.M., \& Thøgersen-Ntoumani, C. (2011). Psychological need thwarting in the sport context: Assessing the darker side of athletic experience. Journal of Sport and Exercise Psychology, 33, 75-102. doi: 10.1123/jsep.33.1.75

Bauer, D.J., \& Curran, P.J. (2003). Distributional assumptions of growth mixture models overextraction of latent trajectory classes. Psychological Methods, 8, 338-363. doi: 10.1037/1082989X.8.3.338

Beaton, D.E., Bombardier, C., Guillemin, F., \& Ferraz, M.B. (2000). Guidelines for the process of cross-cultural adaptation of self-report measures. Spine, 25, 3186-3191. doi: 10.1097/00007632200012150-00014

Bidee, J., Vantilborgh, T., Pepermans, R., Griep, Y., \& Hofmans, J. (2016). Temporal dynamics of need satisfaction and need frustration. Two sides of the same coin? European Journal of Work and Organizational Psychology, 25, 900-913. doi: 10.1080/1359432X.2016.1176021

Blažun, H., Kokol, P., \& Vošner, J. (2015). Research literature production on nursing competences from 1981 till 2012: A bibliometric snapshot. Nurse Education Today, 35, 673-679. doi: 10.1016/j.nedt.2015.01.002

Boone, L., Vansteenkiste, M., Soenens, B., der Kaap-Deeder, V., \& Verstuyf, J. (2014). Self-critical perfectionism and binge eating symptoms: A longitudinal test of the intervening role of psychological need frustration. Journal of Counseling Psychology, 61, 363-373. doi: $10.1037 / \mathrm{a} 0036418$

Brunet, J., Gunnell, K.E., Teixeira, P., Sabiston, C.M., \& Bélanger, M. (2016). Should we be looking at the forest or the trees? Overall psychological need satisfaction and individual needs as predictors of physical activity. Journal of Sport \& Exercise Psychology, 38, 317-330. doi: 10.1123/jsep.2016-0256

Chang, L.-C. (2012). An interaction effect of leisure self-determination and leisure competence on older adults' self-rated health. Journal of Health Psychology, 17, 324-332. doi: $10.1177 / 1359105311415727$

Cheung, G. W. (2009). A multiple-perspective approach to data analysis in congruence research. Organizational Research Methods, 12, 63-68. doi: 10.1177/1094428107310091

Childs, J.H., \& Stoeber, J. (2010). Self-oriented, other-oriented, and socially prescribed perfectionism in employees: Relationships with burnout and engagement. Journal of Workplace Behavioral Health, 25, 269-281. doi: 10.1080/15555240.2010.518486

Ciarrochi, J., Morin, A.J.S., Sahdra, B.K., Litalien, D., \& Parker, P.D. (2017). A longitudinal personcentered perspective on youth social support: Relations with psychological wellbeing. Developmental Psychology, 53, 1154-1169. doi: 10.1037/dev0000315

Collins, L.M., \& Lanza, S.T. (2010). Latent class and latent transition analysis: With applications in the social, behavioral, and health sciences. New York, NY, USA: Wiley.

De Gieter, S., Hofmans, J., \& Bakker, A.B. (2018). Need satisfaction at work, job strain, and performance: A diary study. Journal of Occupational Health Psychology, 23, 361-372. doi: 10.1037/ocp0000098 
Deci, E.L., \& Ryan, R.M. (2000). The "what" and "why" of goal pursuits: Human needs and the selfdetermination of behavior. Psychological Inquiry, 11, 227-268. doi: 10.1207/S15327965PLI1104 01

Deci, E.L., \& Ryan, R.M. (2008). Self-determination theory: A macrotheory of human motivation, development, and health. Canadian Psychology, 49, 182-185. doi: 10.1037/a0012801

Deci, E.L., Olafsen, A.H., \& Ryan, R.M. (2017). Self-determination theory in work organizations. Annual Review of Organizational Psychology \& Organizational Behavior, 4, 19-43. doi: 10.1146/annurev-orgpsych-032516-113108

Diallo, T.M.O., Morin, A.J.S., \& Lu, H. (2016). Impact of misspecifications of the latent variancecovariance and residual matrices on the class enumeration accuracy of growth mixture models. Structural Equation Modeling, 23, 507-531. doi: 10.1080/10705511.2016.1169188

Diallo, T.M.O., Morin, A.J.S., \& Lu, H. (2017). The impact of total and partial inclusion or exclusion of active and inactive time invariant covariates in growth mixture models. Psychological Methods, 22, 166-190. doi: 10.1037/met0000084

Dunn, T.J., Baguley, T., \& Brunsden, V. (2014). From alpha to omega: A practical solution to the pervasive problem of internal consistency estimation. British Journal of Psychology, 105, 399412. doi: 10.1111/bjop. 12046

Dysvik, A., Kuvaas, B., \& Gagné, M. (2013). An investigation of the unique, synergistic and balanced relationships between basic psychological needs and intrinsic motivation. Journal of Applied Social Psychology, 43, 1050-1064. doi: 10.1111/jasp. 12068

Edwards, J.R. (2002). Alternatives to difference scores: Polynomial regression and response surface methodology. In F. Drasgow \& N.W. Schmitt (Eds.), Advances in measurement and data analysis (pp. 350-400). San Francisco, CA, USA: Jossey-Bass. doi: 10.1037/e576892011-020

Edwards, J.R. (2009). Latent variable modeling in congruence research: Current problems and future directions. Organizational Research Methods, 12, 34-62. doi: 10.1177/1094428107308920

Enders, C.K. (2010). Applied missing data analysis. New York, NY, USA: Guilford.

Freund, A. (2005). Commitment and job satisfaction as predictors of turnover intentions among welfare workers. Administration in Social Work, 29, 5-21. doi: 10.1300/J147v29n02_02

Gagné, M. (2003). Autonomy support and need satisfaction in the motivation and well-being of gymnasts. Journal of Applied Sport Psychology, 15, 372-390. doi: 10.1080/714044203

Garn, A.C., Morin, A.J.S., \& Lonsdale, C. (2018). Basic psychological need satisfaction toward learning: A longitudinal test of mediation using bifactor exploratory structural equation modeling. Journal of Educational Psychology. Advance online publication. doi: 10.1037/edu0000283

Gaudreau, P., \& Thompson, A. (2010). Testing a $2 \times 2$ model of dispositional perfectionism. Personality and Individual Differences, 48, 532-537. doi: 10.1016/j.paid.2009.11.031

Gillet, N., Fouquereau, E., Huyghebaert, T., \& Colombat, P. (2015). The effects of job demands and organizational resources through psychological need satisfaction and thwarting. The Spanish Journal of Psychology, 18, 1-19. doi: 10.1017/sjp.2015.30

Gillet, N., Morin, A.J.S., Choisay, F. \& Fouquereau, E (2019). A person-centered representation of basic need satisfaction balance at work. Journal of Personnel Psychology. Advance online publication. doi: 10.1027/1866-5888/a000228

Gillet, N., Morin, A.J.S, Huart, I., Colombat, P., \& Fouquereau, E. (2019). The forest and the trees: Investigating the globality and specificity of employees' basic need satisfaction at work. Journal of Personality Assessment. Advance online publication. doi: 10.1080/00223891.2019.1591426

Gillet, N., Morin, A.J.S., Huyghebaert, T., Burger, L., Maillot, A., Poulin, A., \& Tricard, E. (2019). University students' need satisfaction trajectories: A growth mixture analysis. Learning \& Instruction, 60, 275-285. doi: 10.1016/j.learninstruc.2017.11.003

Gillet, N., Morin, A. J., Huyghebaert-Zouaghi, T., Alibran, E., Barrault, S., \& Vanhove-Meriaux, C. (2019). Students' need satisfaction profiles: Similarity and change over the course of a university semester. Applied Psychology. doi: 10.1111/apps.12227

Gillet, N., Morin, A.J.S., \& Reeve, J. (2017). Stability, change, and implications of students' motivation profiles: A latent transition analysis. Contemporary Educational Psychology, 51, 222-239. doi: 10.1016/j.cedpsych.2017.08.006

Gillet, N., Rosnet, E., \& Vallerand, R.J. (2008). Développement d'une échelle de satisfaction des 
besoins fondamentaux en contexte sportif. Canadian Journal of Behavioural Science, 40, 230237. doi: $10.1037 / \mathrm{a} 0013201$

Graham, J.W. (2009). Missing data analysis: Making it work in the real world. Annual Review of Psychology, 60, 549-576. doi: 10.1146/annurev.psych.58.110405.085530

Harju, L.K., Hakanen, J.J., \& Schaufeli, W.B. (2016). Can job crafting reduce job boredom and increase work engagement? A three-year cross-lagged panel study. Journal of Vocational Behavior, 95, 11-20. doi: 10.1016/j.jvb.2016.07.001

Hassard, J., Teoh, K. R., Visockaite, G., Dewe, P., \& Cox, T. (2018). The cost of work-related stress to society: A systematic review. Journal of Occupational Health Psychology, 23, 1-17. doi: 10.1037/ocp0000069

Henson, J.M., Reise, S.P., \& Kim, K.H. (2007). Detecting mixtures from structural model differences using latent variable mixture modeling: A comparison of relative model fit statistics. Structural Equation Modeling, 14, 202-226. doi: 10.1080/10705510709336744

Hetland, J., Hetland, H., Bakker, A.B., Demerouti, E., Andreassen, C.S., \& Pallesen, S. (2015). Psychological need fulfillment as a mediator of the relationship between transformational leadership and positive job attitudes. Career Development International, 20, 464-481. doi: 10.1108/CDI-10-2014-0136

Hewitt, P.L., \& Flett, G.L. (1991). Dimensions of perfectionism in unipolar depression. Journal of Abnormal Psychology, 100, 98-101. doi: 10.1037/0021-843X.100.1.98

Hiemer, J., \& Andresen, M. (2019). "Because work time is life time"- Employees' perceptions of individual overemployment, its causes and its consequences. Frontiers in Psychology, 10, 1920. doi: 10.3389/fpsyg.2019.01920

Hipp, J.R., \& Bauer, D.J. (2006). Local solutions in the estimation of growth mixture models. Psychological Methods, 11, 36-53. doi: 10.1037/1082-989X.11.1.36

Huyghebaert, T., Gillet, N., Fernet, C., Lahiani, F.J., Chevalier, S., \& Fouquereau, E. (2018). Investigating the longitudinal effects of surface acting on managers' functioning through psychological needs. Journal of Occupational Health Psychology, 23, 207-222. doi: 10.1037/ocp0000080

Huyghebaert, T., Gillet, N., Fernet, C., Lahiani, F. J., \& Fouquereau, E. (2018). Leveraging psychosocial safety climate to prevent ill-being: The mediating role of psychological need thwarting. Journal of Vocational Behavior, 107, 111-125. doi: 10.1016/j.jvb.2018.03.010

Huyghebaert, T., Gillet, N., Lahiani, F.J., Dubois-Fleury, A., \& Fouquereau, E. (2018). Psychological safety climate as a human resource development target: Effects on workers functioning through need satisfaction and thwarting. Advances in Developing Human Resources, 20, 169-181. doi: $10.1177 / 1523422318756955$

Ilardi, B.C., Leone, D., Kasser, T., \& Ryan, R.M. (1993). Employee and supervisor ratings of motivation: Main effects and discrepancies associated with job satisfaction and adjustment in a factory setting. Journal of Applied Social Psychology, 23, 1789-1805. doi: 10.1111/j.15591816.1993.tb01066.x

Jang, H., Reeve, J., Ryan, R.M., \& Kim, A. (2009). Can self-determination theory explain what underlies the productive, satisfying learning experiences of collectivistically oriented Korean students? Journal of Educational Psychology, 101, 644-661. doi: 10.1037/a0014241

Jeličič, H., Phelps, E., \& Lerner, R.M. (2009). Missing data methods in longitudinal studies: The persistence of bad practices. Developmental Psychology, 45, 1195-1199. doi: 10.1037/a0015665

Jowett, G.E., Hill, A., Hall, H., \& Curran, T. (2016). Perfectionism, burnout and engagement in youth sport: The mediating role of basic psychological needs. Psychology of Sport \& Exercise, 24, 18 26. doi: 10.1016/j.psychsport.2016.01.001

Kam, C., Morin, A.J.S., Meyer, J.P., \& Topolnytsky, L. (2016). Are commitment profiles stable and predictable? A latent transition analysis. Journal of Management, 42, 1462-1490. doi: $10.1177 / 0149206313503010$

Kazemi, A., \& Ziaaddini, M. (2014). Relationship between perfectionism, psychological hardiness, and job burnout of employees at executive organizations. International Journal of Academic Research in Business and Social Sciences, 4, 160-170. doi: 10.6007/IJARBSS/v4-i3/686

Kendall-Gallagher, D., \& Blegen, M. A. (2009). Competence and certification of registered nurses and safety of patients in intensive care units. American Journal of Critical Care, 18, 106-113. doi: 
$10.4037 /$ ajcc2009487

Keyes, C.L.M. (2005). Mental illness and/or mental health? Investigating axioms of the complete state model of health. Journal of Consulting and Clinical Psychology, 73, 539-548. doi:

10.1037/0022-006X.73.3.539

Larsen, R. (2011). Missing data imputation versus full information maximum likelihood with second level dependencies. Structural Equation Modeling, 18, 649-662. doi: 10.1080/10705511.2011.607721

Locke, E.A. (1976). The nature and causes of job satisfaction. In M.D. Dunnette (Ed.), Handbook of Industrial and Organizational Psychology (Vol. 1, pp. 1297-1343). Chicago, IL, USA: Rand McNally.

Lubke, G., \& Muthén, B.O. (2007). Performance of factor mixture models as a function of model size, covariate effects, and class-specific parameters. Structural Equation Modeling, 14, 26-47. doi: $10.1080 / 10705510709336735$

Marsh, H.W., Lüdtke, O., Trautwein, U., \& Morin, A.J.S. (2009). Classical latent profile analysis of academic self-concept dimensions: Synergy of person- and variable-centered approaches to theoretical models of self-concept. Structural Equation Modeling, 16, 191-225. doi: $10.1080 / 10705510902751010$

McDonald, R. (1970). Theoretical foundations of principal factor analysis, canonical factor analysis, and alpha factor analysis. British Journal of Mathematical \& Statistical Psychology, 23, 1-21. doi: 10.1111/j.2044-8317.1970.tb00432.x

McLachlan, G., \& Peel, D. (2000). Finite mixture models. New York, NY, USA: Wiley. doi: $10.1002 / 0471721182$

McLarnon, M.J.W., \& O'Neill, T.A. (2018). Extensions of auxiliary variable approaches for the investigation of mediation, moderation, and conditional effects in mixture models.

Organizational Research Methods. Advance online publication. doi: $10.1177 / 1094428118770731$

Meyer, J.P., \& Morin, A.J.S. (2016). A person-centered approach to commitment research: Theory, research, and methodology. Journal of Organizational Behavior, 37, 584-612. doi: 10.1002/job.2085

Millsap, R.E. (2011). Statistical approaches to measurement invariance. New York, NY, USA: Taylor \& Francis. doi: 10.4324/9780203821961

Mitchelson, J.K. (2009). Seeking the perfect balance: Perfectionism and work-family conflict. Journal of Occupational and Organizational Psychology, 82, 349-367. doi: 10.1348/096317908X314874

Morin, A.J.S., Boudrias, J.-S., Marsh, H.W., Madore, I., \& Desrumaux, P. (2016). Further reflections on disentangling shape and level effects in person-centered analyses: An illustration aimed at exploring the dimensionality of psychological health. Structural Equation Modeling, 23, 438454. doi: 10.1080/10705511.2015.1116077

Morin, A.J.S., Boudrias, J.-S., Marsh, H.W., McInerney, D.M., Dagenais-Desmarais, V., Madore, I., \& Litalien, D. (2017). Complementary variable- and person-centered approaches to exploring the dimensionality of psychometric constructs: Application to psychological wellbeing at work. Journal of Business \& Psychology, 32, 395-419. doi: 10.1007/s10869-016-9448-7

Morin, A.J.S., Bujacz, A., \& Gagné, M. (2018). Person-centered methodologies in the organizational sciences: Introduction to the feature topic. Organizational Research Methods. Advance online publication. doi: 10.1177/1094428118773856

Morin, A.J.S., \& Litalien, D. (2017). Webnote: Longitudinal tests of profile similarity and latent transition analyses. Montreal, QC, CA: Substantive Methodological Synergy Research Laboratory.

Morin, A., \& Litalien, D. (2019). Mixture modeling for lifespan developmental research. In Oxford Research Encyclopedia of Psychology. Oxford University Press. doi: 10.1093/acrefore/9780190236557.013.364

Morin, A.J.S., Maïano, C., Nagengast, B., Marsh, H.W., Morizot, J., \& Janosz, M. (2011). Growth mixture modeling of adolescents trajectories of anxiety: The impact of untested invariance assumptions on substantive interpretations. Structural Equation Modeling, 18, 613-648. doi: $10.1080 / 10705511.2011 .607714$ 
Morin, A.J., \& Marsh, H.W. (2015). Disentangling shape from level effects in person-centered analyses: An illustration based on university teachers' multidimensional profiles of effectiveness. Structural Equation Modeling, 22, 39-59. doi: 10.1080/10705511.2014.919825

Morin, A.J.S., Marsh, H.W., \& Nagengast, B. (2013). Exploratory structural equation modeling. In G.R. Hancock \& R.O. Mueller (Eds.), Structural equation modeling: A second course (2nd ed., pp. 395-436). Charlotte, NC, USA : Information Age.

Morin, A.J.S., Meyer, J.P., Creusier, J., \& Biétry, F. (2016). Multiple-group analysis of similarity in latent profile solutions. Organizational Research Methods, 19, 231-254. doi: $10.1177 / 1094428115621148$

Morin, A.J.S., Myers, N.D., \& Lee, S. (2019). Modern factor analytic techniques: Bifactor models, exploratory structural equation modeling (ESEM) and bifactor-ESEM. In G. Tenenbaum \& R.C. Eklund (Eds.), Handbook of sport psychology (4th ed). London, UK: Wiley.

Muthén, B.O. (2003). Statistical and substantive checking in growth mixture modeling: Comment on Bauer and Curran (2003). Psychological Methods, 8, 369-377. doi: 10.1037/1082-989X.8.3.369

Muthén, L.K., \& Muthén, B. (2015). Mplus user's guide. Los Angeles, CA, USA: Muthén \& Muthén.

Nylund, K.L., Asparouhov, T., \& Muthén, B. (2007). Deciding on the number of classes in latent class analysis and growth mixture modeling: A Monte Carlo simulation study. Structural Equation Modeling, 14, 535-569. doi: 10.1080/10705510701575396

Olafsen, A.H., Halvari, H., Forest, J., \& Deci, E.L. (2015). Show them the money? The role of pay, managerial need support, and justice in a self-determination theory model of intrinsic work motivation. Scandinavian Journal of Psychology, 56, 447-457. doi: 10.1111/sjop.12211

Ozbilir, T., Day, A., \& Catano, V.M. (2015). Perfectionism at work: An investigation of adaptive and maladaptive perfectionism in the workplace among Canadian and Turkish employees. Applied Psychology: An International Review, 64, 252-280. doi: 10.1111/apps.12032

Petrou, P., Demerouti, E., Peeters, M.C., Schaufeli, W.B., \& Hetland, J. (2012). Crafting a job on a daily basis: Contextual correlates and the link to work engagement. Journal of Organizational Behavior, 33, 1120-1141. doi: 10.1002/job.1783

Peugh, J., \& Fan, X. (2013). Modeling unobserved heterogeneity using latent profile analysis: A Monte Carlo simulation. Structural Equation Modeling, 20, 616-639. doi: 10.1080/10705511.2013.824780

Pisanti, R., van der Doef, M., Maes, S., Lazzari, D., \& Bertini, M. (2011). Job characteristics, organizational conditions, and distress/well-being among Italian and Dutch nurses: A crossnational comparison. International Journal of Nursing Studies, 48, 829-837. doi: 10.1016/j.ijnurstu.2010.12.006

Ratelle, C., \& Duchesne, S. (2014). Trajectories of psychological need satisfaction from early to late adolescence as a predictor of school adjustment. Contemporary Educational Psychology, 39, 388-400. doi: 10.1016/j.cedpsych.2014.09.003

Raykov, T., \& Marcoulides, G.A. (2004). Using the delta method for approximate interval estimation of parameter functions in SEM. Structural Equation Modeling, 11, 621-637. doi: $10.1207 / \mathrm{s} 15328007 \mathrm{sem} 1104$ 7

Rice, K.G., Leever, B.A., Christopher, J., \& Porter, J.D. (2006). Perfectionism, stress, and social (dis)connection: A short-term study of hopelessness, depression, and academic adjustment among honors students. Journal of Counseling Psychology, 53, 524-534. doi: 10.1037/00220167.53.4.524

Rice, K.G., Lopez, F.G., \& Richardson, C.M. (2013). Perfectionism and performance among STEM students. Journal of Vocational Behavior, 82, 124-134. doi: 10.1016/j.jvb.2012.12.002

Rice, K.G., Richardson, C.M., \& Tueller, S. (2014). The short form of the revised almost perfect scale. Journal of Personality Assessment, 96, 368-379. doi: 10.1080/00223891.2013.838172

Rudolph, C.W., Katz, I.M., Lavigne, K.N., \& Zacher, H. (2017). Job crafting: A meta-analysis of relationships with individual differences, job characteristics, and work outcomes. Journal of Vocational Behavior, 102, 112-138. doi: 10.1016/j.jvb.2017.05.008

Ryan, R.M. (1995). Psychological needs and the facilitation of integrative processes. Journal of Personality, 63, 397-427. doi: 10.1111/j.1467-6494.1995.tb00501.x

Sánchez-Oliva, D., Morin, A.J.S., Teixeira, P.J., Carraça, E.V., Palmeira, A.L., \& Silva, M.N. (2017). A bifactor exploratory structural equation modelling representation of the structure of the basic 
psychological needs at work scale. Journal of Vocational Behavior, 98, 173-187. doi: 10.1016/j.jvb.2016.12.001

Schaufeli, W.B., Bakker, A.B., \& Salanova, M. (2006). The measurement of work engagement with a short questionnaire. Educational and Psychological Measurement, 66, 701-716. doi: 10.1177/0013164405282471

Sheldon, K.M., \& Filak, V. (2008). Manipulating autonomy, competence, and relatedness support in a game-learning context: New evidence that all three needs matter. British Journal of Social Psychology, 47, 267-283. doi: 10.1348/014466607X238797

Sheldon, K.M., \& Niemiec, C.P. (2006). It's not just the amount that counts: Balanced need satisfaction also affects well-being. Journal of Personality and Social Psychology, 91, 331-341. doi: 10.1037/0022-3514.91.2.331

Skrondal, A., \& Laake, P. (2001). Regression among factor scores. Psychometrika, 66, 563-576. doi: 10.1007/BF02296196

Skrondal, A., \& Rabe-Hesketh, S. (2004). Generalized latent variable modeling: Multilevel, longitudinal, and structural equation models. New York, NY: Chapman \& Hall/CRC.

Slemp, G.R., \& Vella-Brodrick, D.A. (2014). Optimising employee mental health: The relationship between intrinsic need satisfaction, job crafting, and employee well-being. Journal of Happiness Studies, 15, 957-977. doi: 10.1007/s10902-013-9458-3

Sonnentag, S., \& Fritz, C. (2007). The Recovery Experience Questionnaire: Development and validation of a measure for assessing recuperation and unwinding from work. Journal of Occupational Health Psychology, 12, 204-221. doi: 10.1037/1076-8998.12.3.204

Sonnentag, S., Kuttler, I., \& Fritz, C. (2010). Job stressors, emotional exhaustion, and need for recovery: A multi-source study on the benefits of psychological detachment. Journal of Vocational Behavior, 76, 355-365. doi: 10.1016/j.jvb.2009.06.005

Stoeber, J., Davis, C.R., \& Townley, J. (2013). Perfectionism and workaholism in employees: The role of work motivation. Personality and Individual Differences, 55, 733-738. doi: 10.1016/j.paid.2013.06.001

Stoeber, J., \& Otto, K. (2006). Positive conceptions of perfectionism: Approaches, evidence, challenges. Personality and Social Psychology Review, 10, 295-319. doi: $10.1207 / \mathrm{s} 15327957 \mathrm{pspr} 1004 \_2$

Tein, J.-Y., Coxe, S., \& Cham, H. (2013). Statistical power to detect the correct number of classes in latent profile analysis. Structural Equation Modeling, 20, 640-657. doi: 10.1080/10705511.2013.824781

Tims, M., Bakker, A.B., \& Derks, D. (2012). Development and validation of the job crafting scale. Journal of Vocational Behavior, 80, 173-186. doi: 10.1016/j.jvb.2011.05.009

Tofighi, D., \& Enders, C. (2008). Identifying the correct number of classes in growth mixture models. In G.R. Hancock \& K.M. Samuelsen (Eds.), Advances in latent variable mixture models (pp. 317-341). Charlotte, NC, USA : Information Age.

Tóth-Király, I., Bőthe, B., Orosz, G., \& Rigó, A. (2018). On the importance of balanced need fulfillment: A person-centered perspective. Journal of Happiness Studies. doi: 10.1007/s10902018-0066-0

Tóth-Király, I., Morin, A. J. S., Bőthe, B., Orosz, G., \& Rigó, A. (2018). Investigating the multidimensionality of need fulfillment: A bifactor exploratory structural equation modeling representation. Structural Equation Modeling, 25, 267-286. doi: 10.1080/10705511.2017.1374867

Trépanier, S.-G., Fernet, C., \& Austin, S. (2015). A longitudinal investigation of workplace bullying, basic need satisfaction, and employee functioning. Journal of Occupational Health Psychology, 20, 105-116. doi: 10.1037/a0037726

Trépanier, S.-G., Fernet, C., \& Austin, S. (2016). Longitudinal relationships between workplace bullying, basic psychological needs, and employee functioning: A simultaneous investigation of psychological need satisfaction and frustration. European Journal of Work and Organizational Psychology, 25, 690-706. doi: 10.1080/1359432X.2015.1132200

Trépanier, S.G., Forest, J., Fernet, C., \& Austin, S. (2015). On the psychological and motivational processes linking job characteristics to employee functioning: Insights from self-determination theory. Work \& Stress, 29, 286-305. doi: 10.1080/02678373.2015.1074957 
Tziner, A., \& Tanami, M. (2013). Examining the links between attachment, perfectionism, and job motivation potential with job engagement and workaholism. Revista de Psicología del Trabajo $y$ de las Organizaciones, 29, 65-74. doi: 10.5093/tr2013a10

Vallerand, R. J. (1997). Toward a hierarchical model of intrinsic and extrinsic motivation. In M. P. Zanna (Ed.), Advances in experimental social psychology (pp. 271-360). New York, NY, USA: Academic Press. doi: 10.1016/S0065-2601(08)60019-2

Van den Broeck, A., Vansteenkiste, M., De Witte, H., \& Lens, W. (2008). Explaining the relationships between job characteristics, burnout, and engagement: The role of basic psychological need satisfaction. Work \& Stress, 22, 277-294. doi: 10.1080/02678370802393672

Van den Broeck, A., Vansteenkiste, M., De Witte, H., Soenens, B., \& Lens, W. (2010). Capturing autonomy, competence, and relatedness at work: Construction and initial validation of the Work-related Basic Need Satisfaction scale. Journal of Occupational and Organizational Psychology, 83, 981-1002. doi: 10.1348/096317909X481382

Van Veldhoven, M., \& Broersen, S. (2003). Measurement quality and validity of the "need for recovery scale". Occupational and Environmental Medicine, 60, i3-9. doi: 10.1136/oem.60.suppl_1.i3

Van Wingerden, J., Derks, D., \& Bakker, A. (2017). The impact of personal resources and job crafting interventions on work engagement and performance. Human Resource Management, 56, 51-67. doi: $10.1002 / \mathrm{hrm} .21758$

Vansteenkiste, M., Lens, W., Soenens, B., \& Luyckx, K. (2006). Autonomy and relatedness among Chinese sojourners and applicants: Conflictual or independent predictors of well-being and adjustment? Motivation and Emotion, 30, 273-282. doi: 10.1007/s11031-006-9041-x

Wanous, J.P., Reichers, A.E., \& Hudy, M.J. (1997). Overall job satisfaction: how good are single-item measures? Journal of Applied Psychology, 82, 247-252. doi: 10.1037//0021-9010.82.2.247

Wrzesniewski, A., \& Dutton, J.E. (2001). Crafting a job: Revisioning employees as active crafters of their work. Academy of Management Review, 26, 179-201. doi: 10.5465/amr.2001.4378011

Yang, C. (2006). Evaluating latent class analyses in qualitative phenotype identification. Computational Statistics \& Data Analysis, 50, 1090-1104. doi: 10.1016/j.csda.2004.11.004

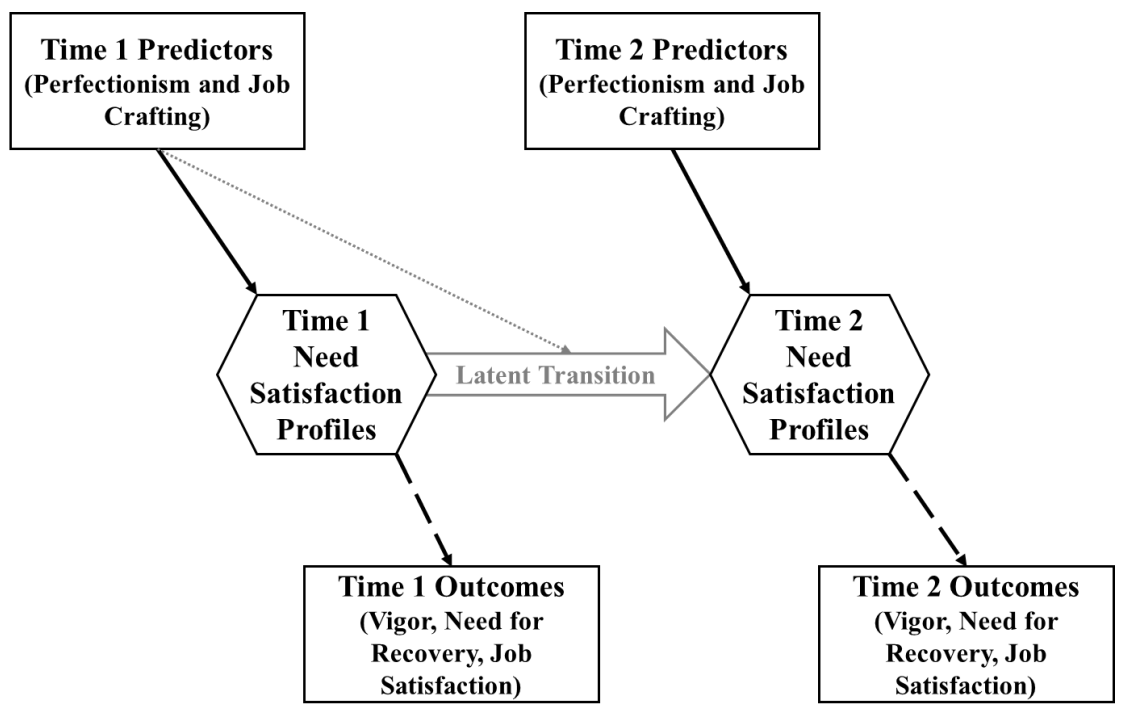

Figure 1. Theoretical model tested in the present study

Note. Hexagons represent the time-specific latent profile solution (which can be more or less similar over time), linked via the latent transition function (reflecting individual changes in profile membership over time, i.e., within-person stability). Time-specific predictors are allowed to predict the likelihood of profile membership at each time point via a multinomial logistic regression link function (full black arrows) which can be similar or different over time, and can be extended to predict specific profile transitions (dotted greyscale arrows). Mean-levels comparisons of the outcome levels observed in each profile across time points (dashed arrows) can also be specified to be similar, or to differ, over time. 


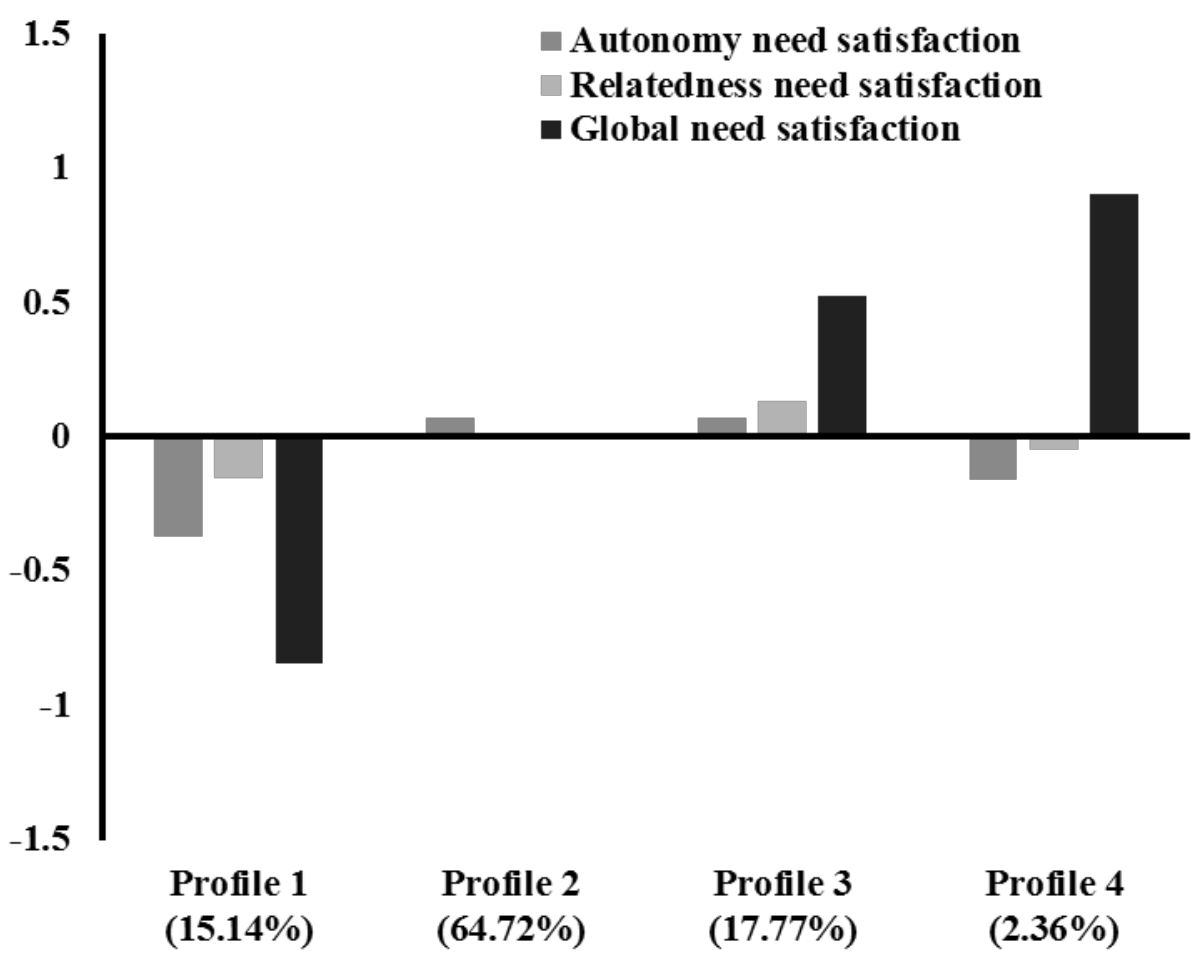

Figure 2. Final 4-profile solution found in this study at both time points.

Note. The profile indicators are estimated from factor scores with mean of 0 and a standard deviation of 1; Profile 1: Globally Dissatisfied; Profile 2: Normative; Profile 3: Moderately Satisfied; Profile 4: Globally Satisfied.

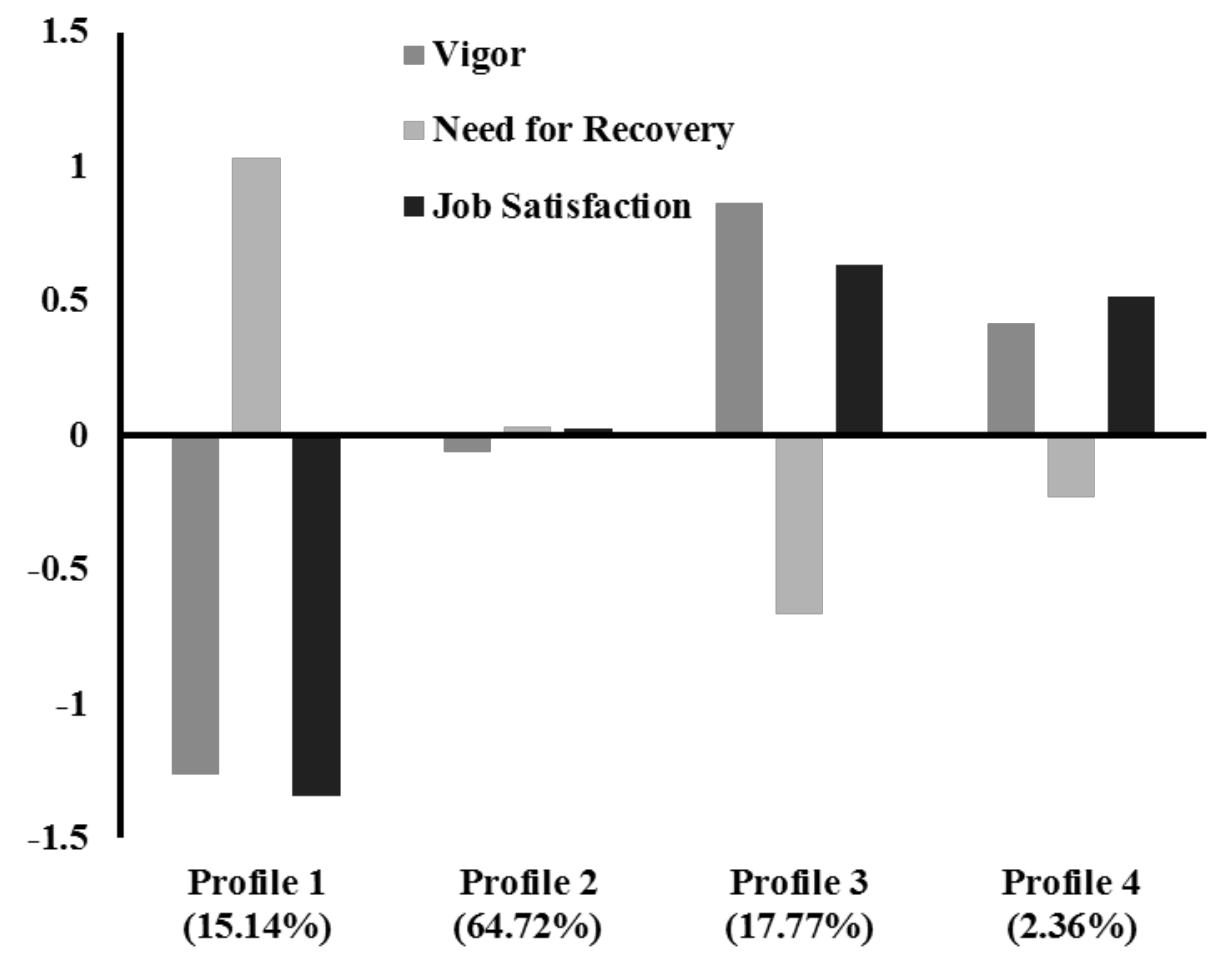

Figure 3. Outcome-levels observed in each of the 4 profiles

Note. Indicators of vigor and need for recovery are estimated from factor scores with mean of 0 and a standard deviation of 1; for consistency, single-item ratings of job satisfaction were standardized prior to the analyses. Profile 1: Globally Dissatisfied; Profile 2: Normative; Profile 3: Moderately Satisfied; Profile 4: Globally Satisfied. 
Table 1

Results from the Latent Profile Analysis Models Estimated Separately at Each Time Point

\begin{tabular}{lcccccccccc}
\hline Model & LL & \#fp & Scaling & AIC & CAIC & BIC & ABIC & Entropy & aLMR & BLRT \\
\hline Time 1 & & & & & & & & & \\
1 Profile & -4465.440 & 6 & 1.507 & 8942.880 & 8979.988 & 8973.988 & 8954.928 & $\mathrm{Na}$ & $\mathrm{Na}$ & $\mathrm{Na}$ \\
2 Profiles & -4187.551 & 13 & 1.308 & 8401.103 & 8481.503 & 8468.503 & 8427.208 & .548 & $<.001$ & $<.001$ \\
3 Profiles & -4117.084 & 20 & 1.331 & 8274.167 & 8397.860 & 8377.860 & 8314.329 & .603 & .044 & $<.001$ \\
4 Profiles & -4005.916 & 27 & 1.685 & 8065.833 & 8232.818 & 8205.818 & 8120.051 & .722 & .118 & $<.001$ \\
5 Profiles & -3968.914 & 34 & 1.657 & 8005.829 & 8216.106 & 8182.106 & 8074.104 & .715 & .444 & $<.001$ \\
6 Profiles & -3929.975 & 41 & 1.449 & 7941.949 & 8195.519 & 8154.519 & 8024.281 & .747 & .082 & $<.001$ \\
7 Profiles & -3905.309 & 48 & 1.391 & 7906.618 & 8203.480 & 8155.480 & 8003.006 & .734 & .207 & $<.001$ \\
8 Profiles & -3843.437 & 55 & 1.408 & 7796.874 & 8137.029 & 8082.029 & 7907.319 & .777 & .191 & $<.001$ \\
\hline Time 2 & & & & & & & & \\
1 Profile & -3749.204 & 6 & 1.801 & 7510.409 & 7547.516 & 7541.516 & 7522.457 & $\mathrm{Na}$ & $\mathrm{Na}$ & $\mathrm{Na}$ \\
2 Profiles & -3346.065 & 13 & 1.332 & 6718.131 & 6798.531 & 6785.531 & 6744.236 & .566 & $<.001$ & $<.001$ \\
3 Profiles & -3278.539 & 20 & 1.231 & 6597.077 & 6720.770 & 6700.770 & 6637.239 & .575 & .003 & $<.001$ \\
4 Profiles & -3211.439 & 27 & 1.229 & 6476.878 & 6643.863 & 6616.863 & 6531.097 & .673 & .010 & $<.001$ \\
5 Profiles & -3181.155 & 34 & 1.562 & 6430.309 & 6640.587 & 6606.587 & 6498.585 & .722 & .689 & $<.001$ \\
6 Profiles & -3150.111 & 41 & 1.238 & 6382.221 & 6635.791 & 6594.791 & 6464.553 & .636 & .208 & $<.001$ \\
7 Profiles & -3111.962 & 48 & 1.401 & 6319.923 & 6616.786 & 6568.786 & 6416.312 & .617 & .438 & $<.001$ \\
8 Profiles & -3094.751 & 55 & 1.327 & 6299.502 & 6639.657 & 6584.657 & 6409.947 & .667 & .264 & $<.001$ \\
\hline
\end{tabular}

Note. LL: model loglikelihood; \#fp: number of free parameters; scaling: scaling correction factor associated with robust maximum likelihood estimates; AIC: Akaïke information criteria; CAIC: constant AIC; BIC: Bayesian information criteria; ABIC: sample size adjusted BIC; aLMR: adjusted Lo-Mendel-Rubin likelihood ratio test; BLRT: bootstrap likelihood ratio test. 
Table 2

Results from the Latent Profile Analyses and Latent Transition Analyses

\begin{tabular}{|c|c|c|c|c|c|c|c|c|}
\hline Model & LL & $\# \mathrm{fp}$ & Scaling & $\mathrm{AIC}$ & CAIC & $\mathrm{BIC}$ & $\mathrm{ABIC}$ & Entropy \\
\hline \multicolumn{9}{|l|}{ Final Latent Profile Analyses } \\
\hline Time 1 & -4005.916 & 27 & 1.685 & 8065.833 & 8232.818 & 8205.818 & 8120.051 & .722 \\
\hline Time 2 & -3211.439 & 27 & 1.229 & 6476.878 & 6643.863 & 6616.863 & 6531.097 & .673 \\
\hline \multicolumn{9}{|l|}{ Longitudinal Latent Profile Analyses } \\
\hline Configural Similarity & -7245.729 & 54 & 1.505 & 14599.457 & 14933.427 & 14879.427 & 14707.894 & .658 \\
\hline Structural Similarity & -7244.534 & 42 & 1.561 & 14573.067 & 14832.821 & 14790.821 & 14657.407 & .686 \\
\hline Dispersion Similarity & -7306.760 & 30 & 1.776 & 14673.520 & 14859.059 & 14829.059 & 14733.762 & .670 \\
\hline Partial Dispersion Similarity & -7248.182 & 39 & 1.492 & 14574.363 & 14815.564 & 14776.564 & 14652.679 & .689 \\
\hline Distributional Similarity & -7251.800 & 36 & 1.710 & 14575.601 & 14798.247 & 14762.247 & 14647.892 & 691 \\
\hline \multicolumn{9}{|l|}{ 3-Step Conversion } \\
\hline Longitudinal Model (replication) & -2321.470 & 6 & 1.000 & 4654.939 & 4692.047 & 4686.047 & 4666.988 & 606 \\
\hline Latent Transition Analysis & -2091.666 & 15 & .5334 & 4213.331 & 4306.101 & 4291.101 & 4243.452 & .862 \\
\hline \multicolumn{9}{|l|}{ Predictive Similarity: Demographics } \\
\hline Null Effects Model & -6232.055 & 35 & .7861 & 12534.110 & 12750.572 & 12715.572 & 12604.394 & .849 \\
\hline Profile-Specific Free Relations with Predictors & -6180.036 & 125 & .5211 & 12610.073 & 13383.151 & 13258.151 & 12861.084 & .835 \\
\hline Free Relations with Predictors & -6209.024 & 65 & 1.0589 & 12548.048 & 12950.049 & 12885.049 & 12678.574 & .849 \\
\hline Equal Relations with Predictors & -6220.415 & 50 & .8567 & 12540.829 & 12850.061 & 12800.061 & 12641.234 & .850 \\
\hline \multicolumn{9}{|l|}{ Predictive Similarity: Predictors } \\
\hline Null Effects Model & -9271.063 & 80 & 1.3277 & 18702.125 & 19196.896 & 19116.896 & 18862.772 & .859 \\
\hline Profile-Specific Free Relations with Predictors & -9163.267 & 170 & .9021 & 18666.535 & 19717.922 & 19547.922 & 19007.910 & .852 \\
\hline Free Relations with Predictors & -9186.885 & 110 & 1.1853 & 18593.770 & 19274.079 & 19164.079 & 18814.660 & .865 \\
\hline Equal Relations with Predictors & -9213.418 & 95 & 1.2948 & 18616.836 & 19204.376 & 19109.376 & 18807.605 & .818 \\
\hline \multicolumn{9}{|l|}{ Explanatory Similarity } \\
\hline Free Relations with Outcomes & -10397.876 & 45 & 1.1123 & 20885.752 & 21164.060 & 21119.060 & 20976.116 & .932 \\
\hline Equal Relations with Outcomes & -10406.837 & 33 & 1.2676 & 20879.673 & 21083.766 & 21050.766 & 20945.940 & .931 \\
\hline
\end{tabular}

Note. LL: model loglikelihood; \#fp: number of free parameters; Scaling: scaling correction factor associated with robust maximum likelihood estimates; AIC: Akaïke information criteria; CAIC: constant AIC; BIC: Bayesian information criteria; ABIC: sample size adjusted BIC. 
Table 3

Transitions Probabilities for the Final Latent Transition Analysis Model

\begin{tabular}{lcccc}
\hline & \multicolumn{4}{c}{ Transition Probabilities to Time 2 Profiles } \\
\cline { 2 - 5 } & Profile 1 & Profile 2 & Profile 3 & Profile 4 \\
\hline Time 1 & & & & \\
Profile 1 & .979 & .021 & .000 & .000 \\
Profile 2 & .000 & 1.000 & .000 & .000 \\
Profile 3 & .002 & .000 & .918 & .080 \\
Profile 4 & .027 & .000 & .850 & .122 \\
\hline
\end{tabular}

Note. Profile 1: Globally Dissatisfied; Profile 2: Normative; Profile 3: Moderately Satisfied; Profile 4: Globally Satisfied.

\section{Table 4}

Results from Multinomial Logistic Regressions for the Effects of the Predictors on Profile Membership (Predictive Similarity)

\begin{tabular}{|c|c|c|c|c|c|c|}
\hline \multirow[b]{2}{*}{ Predictors } & \multicolumn{2}{|c|}{ Profile 1 vs. Profile 4} & \multicolumn{2}{|c|}{ Profile 2 vs. Profile 4} & \multicolumn{2}{|c|}{ Profile 3 vs. Profile 4} \\
\hline & Coef. (SE) & OR & Coef. (SE) & OR & Coef. (SE) & OR \\
\hline Perfectionistic standards & $-1.224(.309)^{* *}$ & .294 & $-1.034(.257)^{* *}$ & .356 & $-.487(.243)^{*}$ & .614 \\
\hline Perfectionistic discrepancies & $1.192(.253)^{* *}$ & 3.292 & $.791(.197)^{* *}$ & 2.206 & $.137(.213)$ & 1.147 \\
\hline Crafting: Increasing Structural Resources & $-.003(.367)$ & .997 & $.654(.301)^{*}$ & 1.923 & $.399(.325)$ & 1.490 \\
\hline Crafting: Increasing Social Resources & $-.739(.300)^{*}$ & .478 & $-.148(.248)$ & .862 & $-.113(.263)$ & .893 \\
\hline \multirow[t]{3}{*}{ Crafting: Increasing Challenging Demands } & $.197(.390)$ & 1.218 & $-.415(.309)$ & .661 & $-.007(.332)$ & .993 \\
\hline & \multicolumn{2}{|c|}{ Profile 1 vs. Profile 3} & \multicolumn{2}{|c|}{ Profile 2 vs. Profile 3} & \multicolumn{2}{|c|}{ Profile 1 vs. Profile 2} \\
\hline & Coef. (SE) & OR & Coef. (SE) & OR & Coef. (SE) & OR \\
\hline Perfectionistic standards & $-.736(.217)^{* *}$ & .479 & $-.546(.152)^{* *}$ & .579 & $-.190(.197)$ & .827 \\
\hline Perfectionistic discrepancies & $1.054(.209)^{* *}$ & 2.869 & $.654(.146)^{* *}$ & 1.923 & $.400(.186)^{*}$ & 1.492 \\
\hline Crafting: Increasing Structural Resources & $-.402(.296)$ & 669 & $.255(.230)$ & 1.291 & $-.657(.260)^{*}$ & .518 \\
\hline Crafting: Increasing Social Resources & $-.626(.214)^{* *}$ & .535 & $-.035(.148)$ & .965 & $-.591(.193)^{* *}$ & .554 \\
\hline Crafting: Increasing Challenging Demands & $.204(.320)$ & 1.226 & $-.408(.237)$ & .665 & $.612(.290$ & 1.844 \\
\hline
\end{tabular}

Note. $* p<.05 ; * p<.01 ;$ SE: standard error of the coefficient; OR: odds ratio; scores on the predictors are estimated from factor scores with mean of 0 and a standard deviation of 1; the coefficients and OR reflects the effects of the predictors on the likelihood of membership into the first listed profile relative to the second listed profile; Profile 1: Globally Dissatisfied; Profile 2: Normative; Profile 3: Moderately Satisfied; Profile 4: Globally Satisfied. 
Table 5

Associations between Profile Membership and the Outcomes Taken from the Model of Explanatory Similarity (Equal across Time Points)

\begin{tabular}{|c|c|c|c|c|c|}
\hline & $\begin{array}{l}\text { Profile 1 } \\
\text { M [CI] }\end{array}$ & $\begin{array}{c}\text { Profile } 2 \\
\mathrm{M}[\mathrm{CI}]\end{array}$ & $\begin{array}{l}\text { Profile } 3 \\
\mathrm{M}[\mathrm{CI}]\end{array}$ & $\begin{array}{l}\text { Profile } 4 \\
\text { M [CI }]\end{array}$ & $\begin{array}{l}\text { Summary of Statistically } \\
\text { Significant Differences }\end{array}$ \\
\hline Vigo & $-1.262[-1.502 ;-1.021]$ & $-.065[-.138 ; .007]$ & $.867[.766 ; .967]$ & $.414[.158 ; .670]$ & 1 \\
\hline Need for & $1.029[.864 ; 1.195]$ & $.033[-.042 ; .109]$ & $-.665[-.777 ;-.554]$ & $-.231[-.543 ; .080]$ & $1>2=4>3$ \\
\hline Job Satisfaction & $-1.345[-1.598 ;-1.093]$ & $.025[-.054 ; .104]$ & $.634[.528 ; .740]$ & $.514[.322 ; .706]$ & $3=4>2>1$ \\
\hline
\end{tabular}

Job Satisfaction $-1.345[-1.598 ;-1.093]$ $.025[-.054 ; .104]$ $.634[.528 ; .740]$ $.514[.322 ; .706]$ $3=4>2>1$

Note. M: mean; CI: $95 \%$ confidence interval; indicators of vigor and need for recovery are estimated from factor scores with mean of 0 and a standard deviation of 1 ; for consistency, single-item ratings of job satisfaction were standardized prior to the analyses; Profile 1: Globally Dissatisfied; Profile 2: Normative; Profile 3: Moderately Satisfied; Profile 4: Globally Satisfied. 
Online Supplements for Need Satisfaction Profiles S1

\section{Online Supplements for:}

A Longitudinal Examination of Nurses' Need Satisfaction Profiles: A Latent Transition Analysis 


\section{Preliminary Measurement Models \\ A Bifactor Operationalization of Global and Specific Levels of Need Satisfaction}

As noted in the main manuscript, accumulating research evidence suggests that ratings of need satisfaction are best represented as simultaneously reflecting respondents' global levels of need satisfaction across all three needs as well as the more specific levels of satisfaction of their needs for competence, relatedness, and autonomy left unexplained by this global level of need satisfaction. This conclusion holds in the educational (Garn, Morin, \& Lonsdale, 2018; Gillet, Morin, Huyghebaert et al., 2019), work (Bidee, Vantilborgh, Pepermans, Griep, \& Hofmans, 2016; Gillet, Morin, Choisay, \& Fouquereau, 2019; Gillet, Morin, Huart, Colombat, \& Fouquereau, 2019; Sánchez-Oliva et al., 2017), sport (Brunet, Gunnell, Teixeira, Sabiston, \& Bélanger, 2016), and general life (Tóth-Király, Morin, Bőthe, Orosz, \& Rigó, 2018) domains. In practical terms, these studies show that it is possible to simultaneously obtain a direct estimate of participants' global levels of need satisfaction across all three needs, together with a non-redundant estimate of the unique satisfaction of each specific need over and above that global level (i.e., expressed as deviations from that global level, and thus directly reflecting imbalance in the satisfaction of each need relative to all others for a specific individual). Importantly, research in which these two layers of measurement cannot be properly disentangled carries the risk of leading to an overly similar assessment of the relative contribution of each psychological need, making it impossible to clearly identify the unique contribution of each need over and above that of global levels of need satisfaction (Gillet, Morin, Choisay, \& Fouquereau, 2019; Sánchez-Oliva et al., 2017; Tóth-Király et al., 2018).

This multidimensional operationalization of need satisfaction is typically achieved via the estimation of bifactor measurement models (e.g., Holzinger \& Swineford, 1937; Morin, Arens, \& Marsh, 2016; Reise, 2012). In bifactor models, all need satisfaction items associated with the three subscales were used to define an overarching G-factor reflecting participants' global levels of need satisfaction. In addition, all subscale-specific items were used to define a S-factor reflecting the unique variance associated with each need left unexplained by the G-factor (i.e., expressed as deviations from the global level). When considering the adequacy of a bifactor solution, Morin et al. (2016) highlight that, whereas the observation of a well-defined G-factor is critical, it is only necessary for some of the S-factors to be similarly well-defined. Morin, Myers, and Lee (in press) add that the observation of weakly defined S-factors simply suggests that the items associated with these specific factors only retain a limited amount of specificity once the variance explained by the global factor is taken into account, and illustrate that bifactor models are notably robust to such "vanishing" S-factors. In terms of need satisfaction, observing a weakly-defined specific factor would thus simply indicate that the items used to assess the satisfaction of the need associated with this specific factor provide a clearer reflection of employees' global levels of need satisfaction than of that more specific need. More precisely, this would reveal that, among the sample under study, this specific need tends to present only negligible amounts of discrepancies or imbalance relative to employees' global levels of need satisfaction.

The previous discussion on "vanishing" S-factors is important as it appears to be the norm in the previous studies in which a bifactor operationalization of need satisfaction was considered. If we ignore two studies in which need satisfaction and frustration have been simultaneously considered, that have both resulted in the identification of multiple "vanishing" S-factors (Bidee et al., 2016; Tóth-Király et al., 2018), it is interesting to note that the nature of the "vanishing" S-factors identified in the remaining studies appears to be context-specific. Thus, in a study of adolescent students involved in mandatory physical education classes, Garn et al. (2018) reported a "vanishing" relatedness S-factor. In contrast, in a study of adolescents' extracurricular sport involvement, Brunet et al. (2016) reported more weakly-defined competence and autonomy S-factors.

Research conducted among populations of University students (Gillet, Morin, Huyghebaert et al., 2019) or among undifferentiated populations of working adults (Gillet, Morin, Choisay, \& Fouquereau, 2019; Gillet, Morin, Huart et al., 2019; Sánchez-Oliva et al., 2017) have generally reported either a "vanishing", or at least a weaker, autonomy S-factor, consistent with the idea that autonomy ratings are a critical driver of global levels of need satisfaction among these populations. These previous results lead us to expect support for a bifactor operationalization of need satisfaction resulting in a well-defined G-factor, but more weakly-defined autonomy, competence, and relatedness S-factors. Although prior research conducted among working adults leads us to expect results 
indicative of a "vanishing" autonomy S-factor, we note that the present sample includes nurses, a working population for whom autonomy is typically very high (e.g., Cajulis \& Fitzpatrick, 2007) and in which concerns are more typically expressed in relation to the ability to express their true abilities in the midst of an accumulation of clerical, administrative, and more technical tasks (e.g., Furåker, 2009), thus leaving the door open to possible differences.

\section{Analyses: Measurement Model Estimation}

Preliminary measurement models were estimated with Mplus 7.4 (Muthén \& Muthén, 2015) using the robust Maximum Likelihood (MLR) estimator, which provides parameter estimates, standard errors, and goodness-of-fit indices that are robust to the non-normality of the response scales used in the present study. These models were estimated using Full Information Maximum Likelihood (FIML; Enders, 2010) procedures to account for the limited amount of missing responses present at the item level for participants who completed each specific time point ( $0 \%$ to $0.90 \%)$. FIML allowed us to estimate longitudinal models using the data from all respondents who completed at least one wave of data rather than using a problematic listwise deletion strategy focusing only on those having participated at both time waves (Enders, 2010; Graham, 2009). In total, 1319 employees participated in this study, with $365(27.7 \%)$ completing both questionnaires and $954(72.3 \%)$ completing only Time 1 or Time 2. FIML has comparable efficacy to multiple imputation, while being more efficient (Enders, 2010; Graham, 2009; Jeličič, Phelps, \& Lerner, 2009; Larsen, 2011).

Due to the complexity of the longitudinal models underlying all constructs assessed in the present study, these preliminary analyses were conducted separately for the need satisfaction measure and the multi-items predictor (perfectionistic standards, perfectionistic discrepancies, increasing structural resources, increasing social resources, and increasing challenging demands) and outcome (vigor and need for recovery) measures. For the need satisfaction measure, a bifactor exploratory structural equation modeling (ESEM) model (e.g., Morin et al., 2016) including one global factor (G-factor: global need satisfaction) and three specific orthogonal factors (S-factors: autonomy, competence, and relatedness) was estimated at each time point. This model is illustrated in Figure S1 of these supplements. This modeling decision is based on accumulated evidence supporting the superiority of this approach within all studies in which a bifactor-ESEM representation of need satisfaction was contrasted with alternative solutions (Garn et al., 2018; Gillet, Morin, Choisay, \& Fouquereau, 2019; Gillet, Morin, Huart et al., 2019; Sánchez-Oliva et al., 2017; Tóth-Király et al., 2018). Yet, to support this decision, we still estimated comparable confirmatory factor analytic (CFA), bifactor-CFA, and ESEM solutions.

Regarding the covariates, we had no reason to expect bifactor solutions to provide a superior representation of any of the constructs. However, on the basis of accumulating statistical evidence supporting the value of incorporating the free estimation of cross-loadings to a model via an ESEM solution for any multidimensional measures (e.g., Asparouhov, Muthén, \& Morin, 2015), ESEM was used to represent all multidimensional measures. More precisely, two correlated CFA factors were used to represent vigor and need for recovery (each estimated using a different measure), a set of two correlated ESEM factors (with cross-loadings freely estimated between them, but not with other constructs) were used to represent both dimensions of perfectionism (standards and discrepancies), and a final set of three correlated ESEM factors (with cross-loadings freely estimated between them, but not with other constructs) were used to represent job crafting dimensions (increasing social resources, increasing structural resources, and increasing challenging demands).

Longitudinal models were directly estimated across all three time waves and included a total of 8 factors ([1 G-factor +3 S-factors $]$ x 2 time waves) for the need satisfaction measure and 14 factors for the predictor and outcome measures ( 7 factors $\times 2$ time waves). All factors were freely allowed to correlate across time points. A priori correlated uniquenesses between matching indicators of the factors utilized at the different time points were included to avoid inflated stability estimates (e.g., Marsh, 2007). ESEM solutions were estimated using an oblique target rotation, whereas bifactorESEM models were estimated using an orthogonal bifactor target rotation in line with bifactor model assumptions of orthogonality (Morin et al., 2016; Reise, 2012). Target rotation is a confirmatory approach to rotation in which all main loadings are specified a priori (as in a CFA model) and allowing for the free estimation of all cross loadings which are "targeted" to be as close to zero as possible. Before saving the factor scores for our main analyses, we verified that the measurement models operated in the same manner across time waves, through sequential tests of measurement 
invariance (Millsap, 2011). For both models, we assessed: (1) configural invariance; (2) weak invariance (loadings); (3) strong invariance (loadings and intercepts); (4) strict invariance (loadings, intercepts, and uniquenesses); (5) invariance of the latent variance-covariance matrix (loadings, intercepts, uniquenesses, and latent variances and covariances); and (6) latent means invariance (loadings, intercepts, uniquenesses, latent variances and covariances, and latent means).

Given the known oversensitivity of the chi-square test of exact fit $\left(\chi^{2}\right)$ to sample size and minor model misspecifications (e.g., Marsh, Hau, \& Grayson, 2005), we relied on sample-size independent goodness-of-fit indices to describe the fit of the alternative models (Hu \& Bentler, 1999): The comparative fit index (CFI), the Tucker-Lewis index (TLI), as well as the root mean square error of approximation (RMSEA) and its $90 \%$ confidence interval. Values greater than .90 for the CFI and TLI indicate adequate model fit, although values greater than .95 are preferable. Values smaller than .08 or .06 for the RMSEA respectively support acceptable and excellent model fit. Like the chisquare, chi-square difference tests present a known sensitivity to sample size and minor model misspecifications so that recent studies suggest complementing this information with changes in CFIs and RMSEAs (Chen, 2007; Cheung \& Rensvold, 2002) in the context of tests of measurement invariance. A $\triangle$ CFI of .010 or less, a $\triangle T L I$ of .010 or less, and a $\triangle$ RMSEA of .015 or less between a more restricted model and the previous one support the invariance hypothesis.

\section{Results: Preliminary Measurement Models}

The goodness-of-fit results from all models are reported in Table S1. These results clearly support the adequacy of the a priori bifactor-ESEM model underlying the need satisfaction measures (with all $\mathrm{CFI} / \mathrm{TLI} \geq .95$, and RMSEA $\leq .06)$ and its superiority relative to the ESEM models $(\triangle \mathrm{CFI}=.012$; $\Delta \mathrm{TLI}=.018 ; \Delta \mathrm{RMSEA}=.007)$, whereas neither the CFA nor the bifactor-CFA solutions were able to achieve a satisfactory level of model fit. Morin et al. (2016) mention that sometimes some of these alternative models would result in a highly similar level of model fit, in which case a detailed examination of parameter estimates is required to select the optimal model. In contrast, in the present study, the superiority of the bifactor-ESEM solution is obvious from the perspective of model fit information, and fully aligned with the results from previous research. This solution was thus retained for tests of measurement invariance. The results from these tests supported the configural, weak, and strong invariance of the model, but not its strict invariance ( $\triangle \mathrm{CFI} / \mathrm{TLI} \geq .010 ; \Delta \mathrm{RMSEA} \geq .015)$. We thus pursued tests of partial strict invariance, in which the equality constraints across time points had to be relaxed on a single need satisfaction indicator. Subsequent steps support the invariance of the latent variances and covariances, and latent means of this model. These results globally show that the measurement models underlying our constructs can be considered to be roughly equivalent across time points.

Parameter estimates from this final model of longitudinal invariance, from which factor scores were extracted for the main analyses, are reported in Table S2. Although only (partial) strict measurement invariance is required to ensure that measurement of the constructs remains equivalent across time waves for models based on factor scores (e.g., Millsap, 2011), there are advantages to saving factor scores from a model of complete measurement invariance, which provides time specific measures that are directly comparable based on a mean of 0 and a standard deviation of 1 at all time waves. When interpreting a bifactor solution, it is important to keep in mind that, because bifactor models rely on two factors to explain the covariance present at the item level for each specific item, factor loadings on G- and S-Factors are typically lower than their first-order counterparts (e.g., Morin et al., 2016). As such, the critical question to ask when interpreting a bifactor solution is whether the G-factor really taps into a meaningful amount of covariance shared among all items, and whether there remains sufficient covariance at the subscale level unexplained by the G-factor to result in the estimation of meaningful S-factors. The bifactor results, reported in Table S2, reveal a well-defined ( $\lambda$ $=.390$ to .816$)$ and reliable $(\omega=.888$ at Time 1 and .890 at Time 2$)$ G-factor, as reasonably well as well-defined autonomy $(\lambda=.264$ to $.582 ; \omega=.577$ at Times 1 and 2$)$ and relatedness $(\lambda=.233$ to .374 ; $\omega=.346$ at Time 1 and .364 at Time 2) S-factors. Still, the fact that these S-Factors retained less specificity does not mean that they are not meaningful, especially when modelled using an approach (i.e., factor scores) that provides a level of control for measurement errors and for associations with the global need satisfaction construct, such as the approach taken in the present study. Perhaps more importantly, one cannot apply reliability standards associated with CFA (or ESEM) models to bifactor (CFA or ESEM) models because the true score variance (i.e., reliable item variance) is divided into 
two components in the context of bifactor models (Morin et al., in press). However, our results also match our expectations in revealing that only a negligible level of specificity remains associated with the competence S-factor. More precisely, our results reveal very small, inconsistent, and nonstatistically significant factor loadings $(\lambda=-.365$ to .388$)$ on the competence S-factor, suggesting that responses to these items mainly serve to define employees' global levels of need satisfaction (i.e., the G-factor) in this study. As such, factor scores on this factor were not retained for further analyses.

Finally, results also support the adequacy of the CFA and ESEM models underlying the covariates measures (with all CFI/TLI $\geq .90$ and RMSEA $\leq .08$ : See Table S1). The tests of measurement invariance conducted on responses to the covariate measures also support their complete measurement invariance across time points $(\Delta \mathrm{CFI} \leq .010 ; \Delta \mathrm{TLI} \leq .010 ; \Delta \mathrm{RMSEA} \leq .015$; and overlapping RMSEA confidence intervals). The final invariant parameter estimates from this measurement model, from which factor scores were extracted from the main analyses, are reported in Table S3. This model resulted in factors that were well-defined through high factor loadings $(\lambda=.326$ to .928$)$, resulting in fully acceptable model-based composite reliability coefficients $(\omega=.585$ to .853 ; McDonald, 1970). The correlations between all variables used in the main analyses (i.e., the factor scores from these final measurement models and single item measures) are reported in Table S4.

\section{References used in this supplement}

Asparouhov, T., Muthén, B., \& Morin, A. J. S. (2015). Bayesian structural equation modeling with cross-loadings and residual covariances. Journal of Management, 41, 1561-1577.

Bidee, J., Vantilborgh, T., Pepermans, R., Griep, Y., \& Hofmans, J. (2016). Temporal dynamics of need satisfaction and need frustration. Two sides of the same coin? European Journal of Work and Organizational Psychology, 25, 900-913.

Brunet, J., Gunnell, K. E., Teixeira, P., Sabiston, C. M., \& Bélanger, M. (2016). Should we be looking at the forest or the trees? Overall psychological need satisfaction and individual needs as predictors of physical activity. Journal of Sport \& Exercise Psychology, 38, 317-330.

Cajulis, C. B., Fitzpatrick, J. J., \& Kleinpell, R. M. (2007). Levels of autonomy of nurse practitioners in an acute care setting. Journal of the American Academy of Nurse Practitioners, 19, 500-507.

Chen, F. F. (2007). Sensitivity of goodness of fit indexes to lack of measurement. Structural Equation Modeling, 14, 464-504.

Cheung, G. W., \& Rensvold, R. B. (2002). Evaluating goodness-of fit indexes for testing measurement invariance. Structural Equation Modeling, 9, 233-255.

Enders, C. K. (2010). Applied missing data analysis. New York, NY: Guilford.

Furåker, C. (2009). Nurses' everyday activities in hospital care. Journal of Nursing Management, 17, 269277.

Garn, A. C., Morin, A. J. S., \& Lonsdale, C. (2018). Basic psychological need satisfaction toward learning: A longitudinal test of mediation using bifactor exploratory structural equation modeling. Journal of Educational Psychology. Advance online publication. doi: 10.1037/edu0000283

Gillet, N., Morin, A. J. S., Choisay, F. \& Fouquereau, E (2019). A person-centered representation of basic need satisfaction balance at work. Journal of Personnel Psychology.

Gillet, N., Morin, A. J. S, Huart, I., Colombat, P., \& Fouquereau, E. (2019). The forest and the trees: Investigating the globality and specificity of employees' basic need satisfaction at work. Journal of Personality Assessment.

Gillet, N., Morin, A. J. S., Huyghebaert, T., Burger, L., Maillot, A., Poulin, A., \& Tricard, E. (2018). University students' need satisfaction trajectories: A growth mixture analysis. Learning \& Instruction, 60, 275-285.

Graham, J. W. (2009). Missing data analysis: Making it work in the real world. Annual Review of Psychology, 60, 549-576.

Holzinger, K. J., \& Swineford, F. (1937). The bi-factor model. Psychometrika, 2, 1-17.

Hu, L.-T., \& Bentler, P. M. (1999). Cutoff criteria for fit indexes in covariance structure analysis: Conventional criteria versus new alternatives. Structural Equation Modeling, 6, 1-55.

Jeličič, H., Phelps, E., \& Lerner, R. M. (2009). Missing data methods in longitudinal studies: The persistence of bad practices. Developmental Psychology, 45, 1195-1199.

Larsen, R. (2011). Missing data imputation versus full information maximum likelihood with second level dependencies. Structural Equation Modeling, 18, 649-662. 
Marsh, H. W. (2007). Application of confirmatory factor analysis and structural equation modeling in sport/exercise psychology. In G. Tenenbaum \& R. C. Eklund (Eds.), Handbook of sport psychology ( $3^{\text {rd }}$ ed., pp. 774-798). New York, NY: Wiley.

Marsh, H. W., Hau, K., \& Grayson, D. (2005). Goodness of fit in structural equation models. In A. Maydeu-Olivares \& J. J. McArdle (Eds.), Contemporary psychometrics (pp. 275-340). Mahwah, NJ: Erlbaum.

McDonald, R. P. (1970). Theoretical foundations of principal factor analysis, canonical factor analysis, and alpha factor analysis. British Journal of Mathematical \& Statistical Psychology, 23, 1-21.

Millsap, R. E. (2011). Statistical approaches to measurement invariance. New York: Taylor \& Francis.

Morin, A. J. S., Arens, A., \& Marsh, H. (2016). A bifactor exploratory structural equation modeling framework for the identification of distinct sources of construct-relevant psychometric multidimensionality. Structural Equation Modeling, 23, 116-139.

Morin, A. J. S., Myers, N. D., \& Lee, S. (in press). Modern factor analytic techniques: Bifactor models, exploratory structural equation modeling (ESEM) and bifactor-ESEM. In G. Tenenbaum \& R.C. Eklund (Eds.), Handbook of sport psychology (4th $\mathrm{ed})$. London, UK: Wiley.

Muthén, L. K., \& Muthén, B. O. (2015). Mplus user's guide. Los Angeles, CA: Muthén \& Muthén.

Reise, S. P. (2012). The rediscovery of bifactor measurement models. Multivariate Behavioral Research, 47, 667-696.

Sánchez-Oliva, D., Morin, A. J. S., Teixeira, P. J., Carraça, E. V., Palmeira, A. L., \& Silva, M. N. (2017). A bifactor exploratory structural equation modelling representation of the structure of the Basic Psychological Needs at Work Scale. Journal of Vocational Behavior, 98, 173-187.

Tóth-Király, I., Morin, A. J. S., Bőthe, B., Orosz, G., \& Rigó, A. (2018). Investigating the multidimensionality of need fulfillment: A bifactor exploratory structural equation modeling representation. Structural Equation Modeling, 25, 267-286.

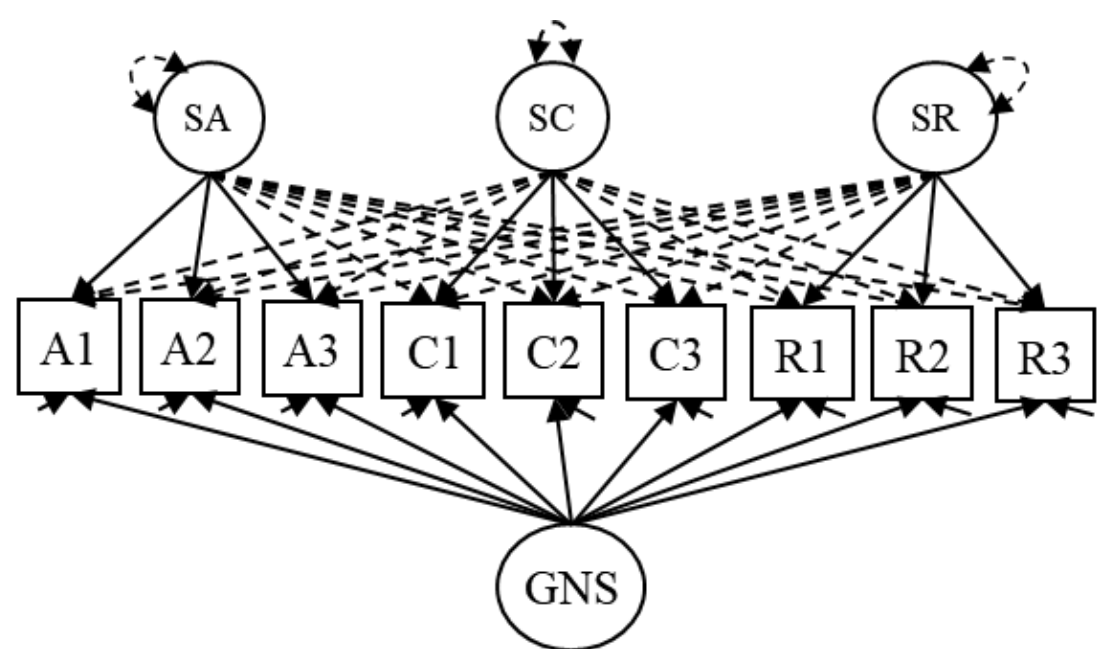

\section{Figure S1}

Graphical Illustration of the Bifactor-ESEM Representation of Need Satisfaction Ratings.

Note. GNS: Global need satisfaction factor; SA: Specific autonomy satisfaction factor; SC: Specific competence satisfaction factor; SR: Specific relatedness satisfaction factor; A1-A3: Autonomy need satisfaction items 1 to 3; C1-C3: Competence need satisfaction items 1 to 3; R1-R3: Relatedness need satisfaction items 1 to 3; Ovals represent latent factors and squares represent observed variables; full unidirectional arrows linking ovals and squares represent factor loadings; dotted unidirectional arrows linking ovals and squares represent the cross-loadings (freely estimated but targeted to be as close to zero as possible); full unidirectional arrows linked to the items represent the item uniquenesses; bidirectional arrows connecting a single oval are factor variances 
Table S1

Goodness-of-Fit Statistics for the Estimated Measurement Models

\begin{tabular}{|c|c|c|c|c|c|c|c|c|c|}
\hline Description & $\chi^{2}(d f)$ & CFI & TLI & RMSEA & $90 \% \mathrm{CI}$ & $\Delta \chi^{2}(d f)$ & $\Delta \mathrm{CFI}$ & $\Delta \mathrm{TLI}$ & $\triangle \mathrm{RMSE}$ \\
\hline \multicolumn{10}{|l|}{ Need Satisfaction } \\
\hline CFA: Unconstrained longitudinal model & $413.880(111)^{*}$ & .920 & .890 & .045 & {$[.041 ; .050]$} & - & - & - & - \\
\hline Bifactor-CFA: Uncol & $2(92)^{*}$ & .937 & .895 & .044 & $.039 ; .050]$ & - & - & 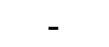 & - \\
\hline ESEM: Unconstrained lor & $170.478(87)^{*}$ & .978 & .961 & .027 & $.021 ; .033]$ & - & - & 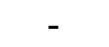 & - \\
\hline Bifactc & 104.3 & .990 & .979 & .020 & $012 ; .028]$ & - & - & - & - \\
\hline Bifact & 104.3 & .990 & .979 & .020 & $012 ; .028]$ & & & - & 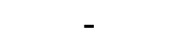 \\
\hline Bif & & .990 & .983 & .01 & & $23.007(20)$ & .000 & +.005 & -.002 \\
\hline Bif & 12 & .992 & .988 & .01 & 2] & .692(5) & +.002 & +.005 & -.003 \\
\hline Bifa & 236.4 & .965 & 947 & .03 & $.026 ; .037]$ & $20.686(9) *$ & -.027 & -.041 & +.017 \\
\hline Bifa & 142. & .989 & .983 & .01 & $.024]$ & $4.810(8)^{*}$ & -.003 & -.005 & +.003 \\
\hline Bif & 136. & .993 & .991 & .013 & {$[.000 ; .020]$} & $4.078(10)$ & +.004 & +.008 & -.005 \\
\hline Bifactor-ESEM: Latent $\mathrm{m}$ & 155.1 & .989 & .986 & .016 & {$[.009 ; .022]$} & $18.779(4)^{*}$ & -.004 & -.005 & -.003 \\
\hline \multicolumn{10}{|l|}{ Predictors and Outcomes } \\
\hline & & 967 & .960 & .02 & & & - & 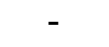 & - \\
\hline & & 966 & .961 & .02 & & 41 & 001 & +.001 & .000 \\
\hline & & 966 & .961 & .02 & & 24.5 & .000 & .000 & .000 \\
\hline $\mathrm{L}$ & 99 & 964 & .960 & .020 & 022] & $49.864(25)^{*}$ & ${ }^{*}-.002$ & -.001 & .000 \\
\hline 1: Varia & $1743.297(1130)^{*}$ & .963 & .960 & .020 & {$[.018 ; .022]$} & $43.702(28)$ & -.001 & .000 & .000 \\
\hline Longitudinal: Latent means invariance & $1771.281(1137)^{*}$ & .962 & .959 & .021 & {$[.019 ; .022]$} & $28.890(7)^{*}$ & -.001 & -.001 & +.001 \\
\hline
\end{tabular}

Note. ${ }^{*} p<.01 ; \chi^{2}$ : scaled chi-square test of exact fit; $d f$ : degrees of freedom; CFI: comparative fit index; TLI: Tucker-Lewis index; RMSEA: root mean square error of approximation; $90 \%$ CI: $90 \%$ confidence interval; Var-Cov: variance-covariance; $\Delta$ : change in fit information relative to the previous model. 
Table S2

Standardized Factor Loadings ( $\lambda)$ and Uniquenesses $(\delta)$ from the Final Longitudinal Bifactor-ESEM Solution for the Need Satisfaction Measure (Latent Mean Invariance)

\begin{tabular}{|c|c|c|c|c|c|c|c|c|c|c|}
\hline \multirow{2}{*}{ Items } & \multirow{2}{*}{$\begin{array}{c}\text { Time } 1 \\
\mathrm{G} \lambda\end{array}$} & \multicolumn{9}{|c|}{ Time 2} \\
\hline & & S-AS $\lambda$ & $\operatorname{S}-\operatorname{CS} \lambda$ & S-RS $\lambda$ & $\delta$ & $\mathrm{G} \lambda$ & S-AS $\lambda$ & $\mathrm{S}-\mathrm{CS} \lambda$ & S-RS $\lambda$ & $\delta$ \\
\hline \multicolumn{11}{|l|}{ Autonomy } \\
\hline Item 1 & .606 & .264 & -.104 & .010 & .552 & .606 & .264 & -.104 & .010 & .552 \\
\hline Item 2 & .566 & .462 & .045 & .064 & .460 & .566 & .462 & .045 & .064 & .460 \\
\hline Item 3 & .642 & .582 & .069 & .000 & .244 & .642 & .582 & .069 & .000 & .244 \\
\hline$\omega$ & & .577 & & & & & .577 & & & \\
\hline \multicolumn{11}{|l|}{ Competence } \\
\hline Item 1 & .816 & -.203 & -.365 & -.033 & .159 & .816 & -.203 & -.365 & -.033 & .159 \\
\hline Item 2 & .687 & .348 & .156 & .004 & .383 & .687 & .348 & .156 & .004 & .383 \\
\hline Item 3 & .698 & -.191 & .388 & -.032 & .325 & .698 & -.191 & .388 & -.032 & .325 \\
\hline$\omega$ & & & .488 & & & & & .488 & & \\
\hline \multicolumn{11}{|l|}{ Relatedness } \\
\hline Item 1 & .390 & -.015 & -.190 & .233 & .757 & .429 & -.016 & -.209 & .256 & .706 \\
\hline Item 2 & .587 & .022 & .060 & .374 & .511 & .587 & .022 & .060 & .374 & .511 \\
\hline Item 3 & .565 & .108 & .127 & .366 & .520 & .565 & .108 & .127 & .366 & .520 \\
\hline$\omega$ & .888 & & & .346 & & .890 & & & .364 & \\
\hline
\end{tabular}

Note. $\mathrm{G}=$ global factor estimated as part of a bifactor model; $\mathrm{S}=$ specific factor estimated as part of a bifactor model; $\lambda$ : factor loading; $\delta$ : item uniqueness; $\omega$ : omega coefficient of model-based composite reliability; target B-ESEM factor loadings are indicated in bold; AS = autonomy satisfaction; CS = competence satisfaction; $\mathrm{RS}=$ relatedness satisfaction; non-significant parameters $(p \geq .05)$ are marked in italics. 
Table S3

Standardized Factor Loadings ( $\lambda)$ and Uniquenesses $(\delta)$ from the Final Longitudinal Solution (Predictors and Outcomes)

\begin{tabular}{|c|c|c|c|c|}
\hline Items & $\begin{array}{c}\text { Factor } 1 \\
\lambda\end{array}$ & $\begin{array}{c}\text { Factor } 2 \\
\lambda\end{array}$ & $\begin{array}{c}\text { Factor } 3 \\
\lambda\end{array}$ & $\Delta$ \\
\hline \multicolumn{5}{|l|}{ Vigor } \\
\hline Item 1 & .869 & & & .245 \\
\hline Item 2 & .835 & & & .302 \\
\hline Item 3 & .726 & & & .473 \\
\hline$\omega$ & .853 & & & \\
\hline \multicolumn{5}{|c|}{ Need for recovery } \\
\hline Item 1 & .589 & & & .653 \\
\hline Item 2 & .721 & & & .480 \\
\hline Item 3 & .739 & & & .454 \\
\hline Item 4 & .696 & & & .516 \\
\hline Item 5 & .597 & & & .644 \\
\hline$\omega$ & .803 & & & \\
\hline \multicolumn{5}{|c|}{ Perfectionistic standards } \\
\hline Item 1 & .831 & -.170 & & .427 \\
\hline Item 2 & .869 & .014 & & .232 \\
\hline Item 3 & .667 & .161 & & .418 \\
\hline Item 4 & .654 & -.053 & & .605 \\
\hline$\omega$ & .844 & & & \\
\hline \multicolumn{5}{|c|}{ Perfectionistic discrepancies } \\
\hline Item 1 & .497 & .326 & & .479 \\
\hline Item 2 & .072 & .709 & & .439 \\
\hline Item 3 & .092 & .761 & & .341 \\
\hline Item 4 & -.122 & .852 & & .366 \\
\hline$\omega$ & & .812 & & \\
\hline \multicolumn{5}{|c|}{ Increasing structural resources } \\
\hline Item 1 & .928 & .058 & -.223 & .360 \\
\hline Item 2 & .662 & -.015 & .195 & .344 \\
\hline Item 3 & .542 & -.040 & .266 & .451 \\
\hline$\omega$ & .797 & & & \\
\hline \multicolumn{5}{|c|}{ Increasing social resources } \\
\hline Item 1 & .130 & .622 & .010 & .520 \\
\hline Item 2 & -.117 & .547 & .198 & .622 \\
\hline Item 3 & -.018 & .816 & -.093 & .413 \\
\hline$\omega$ & & .717 & & \\
\hline \multicolumn{5}{|c|}{ Increasing challenging demands } \\
\hline Item 1 & .154 & .032 & .583 & .479 \\
\hline Item 2 & .046 & .016 & .605 & .580 \\
\hline Item 3 & .058 & .177 & .387 & .702 \\
\hline$\omega$ & & & .585 & \\
\hline
\end{tabular}

Note. $\lambda$ : factor loading (bold: target factor loadings); $\delta$ : item uniqueness; $\omega$ : omega coefficient of model-based composite reliability; non-significant parameters $(p \geq .05)$ are marked in italics. 
Table S4

Correlations between Variables Used in the Present Study

\begin{tabular}{|c|c|c|c|c|c|c|c|c|c|c|c|c|c|}
\hline Variable & 1 & 2 & 3 & 4 & 5 & 6 & 7 & 8 & 9 & 10 & 11 & 12 & 13 \\
\hline 1. Gender & - & & & & & & & & & & & & \\
\hline 2. Job tenure & $.176^{* *}$ & - & & & & & & & & & & & \\
\hline 3. Work status & $-.161 * *$ & $-.123^{* *}$ & - & & & & & & & & & & \\
\hline 4. Employment type & $.192 * *$ & $.142 * *$ & $.348^{* *}$ & - & & & & & & & & & \\
\hline 5. Vigor (T1) & .016 & -.027 & .014 & .009 & - & & & & & & & & \\
\hline 6. Need for recovery (T1) & $-.070^{*}$ & -.023 & .020 & -.042 & $-.455 * *$ & - & & & & & & & \\
\hline 7. Job Satisfaction (T1) & .038 & -.009 & $-.091 * *$ & $.108 * *$ & .027 & -.028 & - & & & & & & \\
\hline 8. Perfectionistic standards (T1) & .008 & .027 & .009 & -.021 & $.306 * *$ & .045 & $-.067 *$ & - & & & & & \\
\hline 9. Perfectionism discrepancies (T1) & -.023 & .012 & .027 & -.035 & $-.095 * *$ & $.283 * *$ & -.054 & $.573 * *$ & - & & & & \\
\hline 10. Job crafting - Increasing structural resources (T1) & .024 & -.019 & $-.079 * *$ & .009 & $.457 * *$ & $-.066^{*}$ & $.064 *$ & $.381 * *$ & -.053 & - & & & \\
\hline 11. Job crafting - Increasing social resources (T1) & .004 & -.024 & .009 & -.008 & $.374 * *$ & $-.150 * *$ & .033 & $.304 * *$ & $.076^{* *}$ & $.527 * *$ & - & & \\
\hline 12. Job crafting - Increasing challenging demands (T1) & .018 & -.020 & -.040 & .011 & $.363 * *$ & $-.056^{*}$ & .052 & $.300 * *$ & .025 & $.853 * *$ & $.640 * *$ & - & \\
\hline 13. Autonomy need satisfaction (T1) & -.011 & .013 & -.013 & .009 & .056 & $-.084 * *$ & .048 & .008 & .032 & $.133^{* *}$ & $.132 * *$ & $.131 * *$ & - \\
\hline 14. Relatedness need satisfaction (T1) & .018 & $.087^{* *}$ & $-.060 *$ & .039 & $.124 * *$ & -.032 & $.058 *$ & .004 & -.054 & $.065^{*}$ & -.009 & .030 & .047 \\
\hline 15. Global need satisfaction (T1) & -.010 & -.027 & .004 & .016 & $.414 * *$ & $-.229 * *$ & .022 & $.159 * *$ & $-.197^{* *}$ & $.356^{* *}$ & $.238^{* *}$ & $.283^{* *}$ & .052 \\
\hline 16. Vigor (T2) & -.019 & -.019 & .003 & .014 & $.914 * *$ & $-.487 * *$ & .031 & $.272 * *$ & $-.098^{* *}$ & $.429 * *$ & $.457^{* *}$ & $.422 * *$ & .046 \\
\hline 17. Need for recovery (T2) & $-.081 * *$ & -.019 & .028 & -.040 & $-.486 * *$ & $.898 * *$ & -.049 & -.011 & $.196^{* *}$ & $-.099 * *$ & $-.173 * *$ & $-.068 *$ & $-.092 * *$ \\
\hline 18. Job Satisfaction (T2) & -.003 & $.072 * *$ & .041 & $-0,60 *$ & -.001 & -.039 & $-.456^{* *}$ & .012 & .013 & $-.079 * *$ & -.042 & $-.082 * *$ & .002 \\
\hline 19. Perfectionistic standards (T2) & .013 & .038 & .033 & -.002 & $.328 * *$ & .018 & $-.119 * *$ & $.838^{* *}$ & $.469 * *$ & $.279 * *$ & $.313 * *$ & $.289 * *$ & -.026 \\
\hline 20. Perfectionistic discrepancies (T2) & -.040 & .023 & .053 & -.015 & $-.157 * *$ & $.326^{* *}$ & $-.078 * *$ & $.372 * *$ & $.832 * *$ & $-.107 * *$ & .011 & .005 & .003 \\
\hline 21. Job crafting - Increasing structural resources (T2) & .046 & -.006 & $-.102 * *$ & .014 & $.423 * *$ & $-.081 * *$ & $.059 *$ & $.356^{* *}$ & $-.082^{* *}$ & $.908 * *$ & $.567^{* *}$ & $.806^{* *}$ & $.112 * *$ \\
\hline 22. Job crafting - Increasing social resources (T2) & .012 & -.029 & -.007 & -.017 & $.278 * *$ & $-.102 * *$ & .041 & $.300 * *$ & $.139 * *$ & $.425^{* *}$ & $.875^{* *}$ & $.548^{* *}$ & $.118^{* *}$ \\
\hline 23. Job crafting - Increasing challenging demands (T2) & -.034 & -.017 & $-.060^{*}$ & .011 & $.248 * *$ & .033 & $.064 *$ & $.170^{* *}$ & -.028 & $.724 * *$ & $.593 * *$ & $.909 * *$ & $.108 * *$ \\
\hline 24. Autonomy need satisfaction (T2) & -.005 & .004 & -.004 & -.012 & $.061 *$ & $-.113 * *$ & $.072 * *$ & -.016 & -.004 & $.134 * *$ & $.117 * *$ & $.111^{* *}$ & $.801 * *$ \\
\hline 25. Relatedness need satisfaction (T2) & -.005 & .032 & $-.072 * *$ & .043 & $.156^{* *}$ & $-.060^{*}$ & $.107 * *$ & .015 & $-.084^{* *}$ & $.133^{* *}$ & .037 & $.095^{* *}$ & .031 \\
\hline 26. Global need satisfaction (T2) & -.007 & .002 & -.033 & -.011 & $.386^{* *}$ & $-.232 * *$ & .005 & $.156^{* *}$ & $-.161 * *$ & $.321 * *$ & $.252 * *$ & $.268 * *$ & $.087 * *$ \\
\hline
\end{tabular}




\section{Table S4 (Continued)}

\begin{tabular}{|c|c|c|c|c|c|c|c|c|c|c|c|c|}
\hline & 14 & 15 & 16 & 17 & 18 & 19 & 20 & 21 & 22 & 23 & 24 & 25 \\
\hline 14. Relatedness need satisfaction (T1) & - & & & & & & & & & & & \\
\hline 15. Global need satisfaction (T1) & $.077 * *$ & - & & & & & & & & & & \\
\hline 16. Vigor (T2) & $.111^{* *}$ & $.402 * *$ & - & & & & & & & & & \\
\hline 17. Need for recovery (T2) & -.052 & $-.241 * *$ & $-.530 * *$ & - & & & & & & & & \\
\hline 18. Job Satisfaction (T2) & $-.080^{* *}$ & .044 & -.040 & -.033 & - & & & & & & & \\
\hline 19. Perfectionistic standards (T2) & .003 & $.148^{* *}$ & $.332 * *$ & -.001 & .030 & - & & & & & & \\
\hline 20. Perfectionistic discrepancies (T2) & $-.075^{* *}$ & $-.210 * *$ & $-.155 * *$ & $.308^{* *}$ & .040 & $.517 * *$ & - & & & & & \\
\hline 21. Job crafting - Increasing structural resources & $.077^{* *}$ & $.337 * *$ & $.495^{* *}$ & $-.111 * *$ & $-.108^{* *}$ & $.350 * *$ & $-.118^{* *}$ & - & & & & \\
\hline 22. Job crafting - Increasing social resources (T2) & .004 & $.210^{* *}$ & $.403 * *$ & $-.170^{* *}$ & -.038 & $.362 * *$ & $.107 * *$ & $.540 * *$ & - & & & \\
\hline 23. Job crafting - Increasing challenging demands & .042 & $.230 * *$ & $.374 * *$ & -.027 & $-.102 * *$ & $.258 * *$ & .003 & $.829 * *$ & $.631 * *$ & - & & \\
\hline 24. Autonomy need satisfaction (T2) & $.128 * *$ & $.108 * *$ & $.071 * *$ & $-.135^{* *}$ & -.038 & $-.057 *$ & -.028 & $.121^{* *}$ & $.145^{* *}$ & $.106^{* *}$ & - & \\
\hline 25. Relatedness need satisfaction (T2) & $.723 * *$ & $.290 * *$ & $.144 * *$ & $-.065^{*}$ & $-.060 *$ & -.018 & $-.097 * *$ & $.129 * *$ & .026 & $.086^{* *}$ & .030 & - \\
\hline 26. Global need satisfaction (T2) & $.209 * *$ & $.756^{* *}$ & $.441 * *$ & $-.249^{* *}$ & -.023 & $.192 * *$ & $-.201 * *$ & $.390 * *$ & $.251 * *$ & $.278^{* *}$ & $.084 * *$ & $.224 * *$ \\
\hline
\end{tabular}

Note. $* p<.05 ; * * p<.01 ;$ T1: Time 1; T2: Time 2; Gender (0- male, 1-female), job tenure (in years), work status (0- part time; 1-full time), and employment type ( 0 - nurse; 1 - assistant nurse) are observed scores reported by the participants; Scores on the other variables are factor scores $(M=0 ; S D=1)$ taken from preliminary measurement models. 


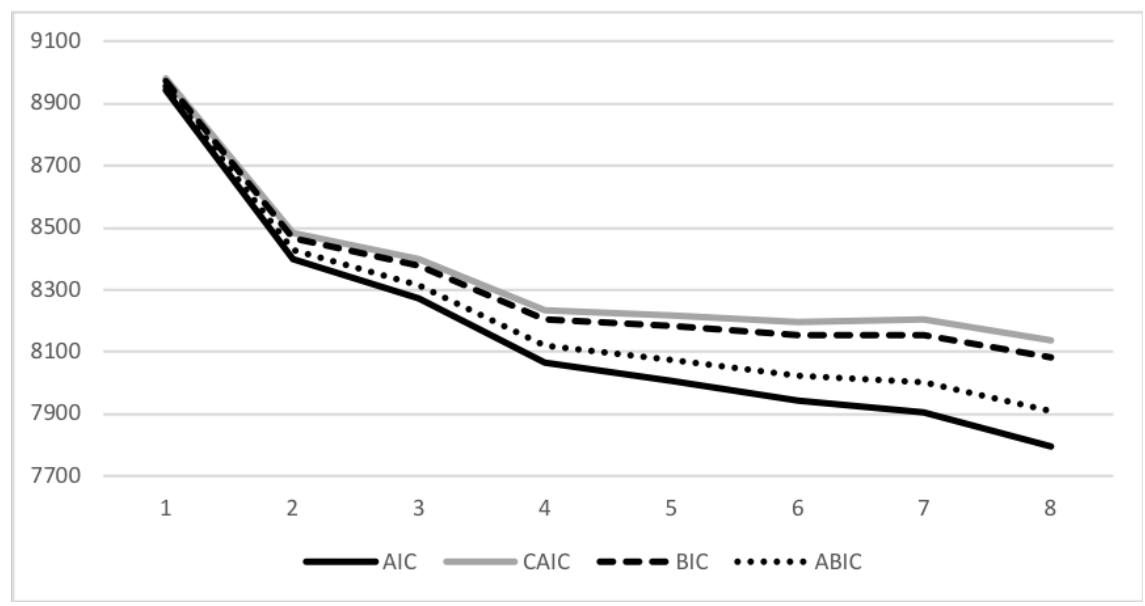

Figure S2

Elbow Plot of the Information Criteria for the Latent Profile Analyses (Time 1)

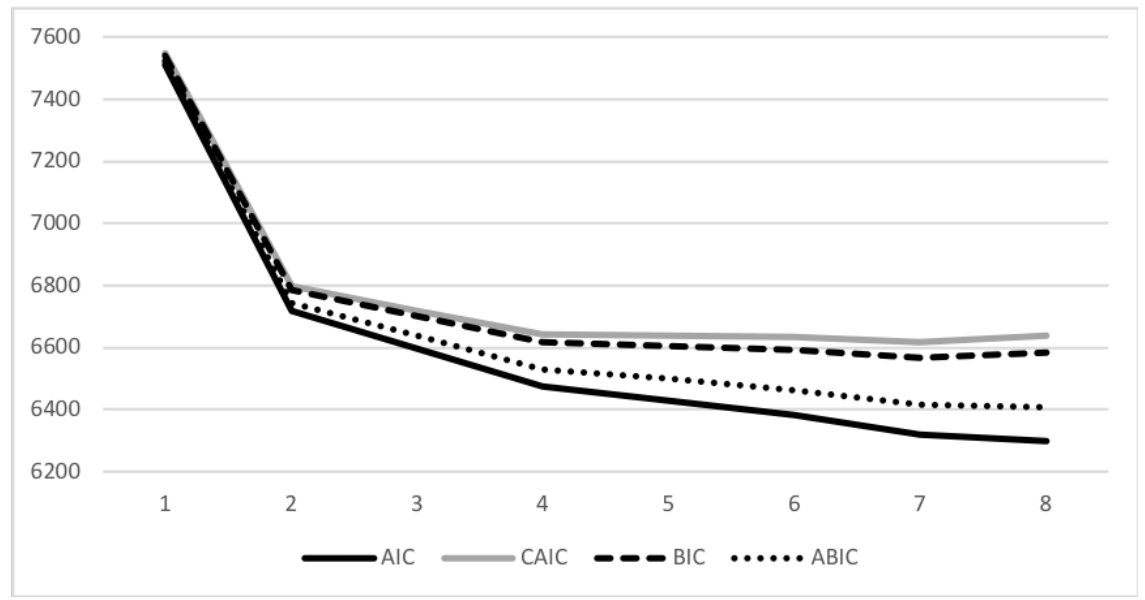

Figure S3

Elbow Plot of the Information Criteria for the Latent Profile Analyses (Time 2) 
Table S5

Detailed Results from the Final Longitudinal Latent Profile Solution (Configural, Structural, Dispersion, and Distributional Similarity)

\begin{tabular}{|c|c|c|c|c|}
\hline & Profile 1 & Profile 2 & Profile 3 & Profile 4 \\
\hline Means (Structural Similarity) & Mean $[\mathrm{CI}]$ & Mean $[\mathrm{CI}]$ & Mean $[\mathrm{CI}]$ & Mean $[\mathrm{CI}]$ \\
\hline Autonomy & $-.374[-.331 ; .225]$ & $.071[-.047 ; .051]$ & $.068[-.062 ; .067]$ & $-.158[-.019 ; .016]$ \\
\hline Relatedness & $-.845[-.137 ; .118]$ & $-.005[-.063 .063]$ & $.135[-.029 ; .034]$ & $-.049[-.006 ; .006]$ \\
\hline Global & $-.152[-.373 ; .148]$ & $.015[-.144 ; .146]$ & $.523[-.050 ; .087]$ & $.903[-.010 ; .026]$ \\
\hline Variances (Time 1) & Variance $[\mathrm{CI}]$ & Variance $[\mathrm{CI}]$ & Variance $[\mathrm{CI}]$ & Variance $[\mathrm{CI}]$ \\
\hline Autonomy & $1.668[-.063 ; .787]$ & $.492[-.098 ; .164]$ & $.081[-.043 ; .047]$ & $.001[-.002 ; .002]$ \\
\hline Relatedness & $.829[-.140 ; .346]$ & $.279[-.071 ; .094]$ & $.048[-.031 ; .032]$ & $.004[-.006 ; .006]$ \\
\hline Global & $1.088[-.175 ; .613]$ & $.673[-.068 ; .140]$ & $.071[-.068 ; .073]$ & $.000[.000 ; .000]$ \\
\hline Variances (Time 2) & Variance $[\mathrm{CI}]$ & Variance $[\mathrm{CI}]$ & Variance $[\mathrm{CI}]$ & Variance $[\mathrm{CI}]$ \\
\hline Autonomy & $1.668[-.063 ; .787]$ & $.300[-.091 ; .124]$ & $.063[-.028 ; .030]$ & $.003[-.002 ; .002]$ \\
\hline Relatedness & $.829[-.140 ; .346]$ & $.154[-.047 ; .055]$ & $.013[-.012 ; .012]$ & $.000[.000 ; .000]$ \\
\hline Global & $1.088[-.175 ; .613]$ & $.410[-.054 ; .083]$ & $.070[-.073 ; .079]$ & $.001[.001 ; .001]$ \\
\hline
\end{tabular}

Note. $\mathrm{CI}=95 \%$ confidence interval; the profile indicators are estimated from factor scores with a standard deviation of 1 and a mean of 0 ; Profile 1: Globally Dissatisfied; Profile 2: Normative; Profile 3: Moderately Satisfied; Profile 4: Globally Satisfied. 